\title{
Fatigue Crack Closure: A Myth or A Misconception?
}

\author{
J. Tong ${ }^{1^{*}}$, S. Alshammrei ${ }^{1}$, B. Lin ${ }^{1}$, T. Wigger ${ }^{1}$, J. Marrow ${ }^{2}$ \\ ${ }^{1}$ University of Portsmouth, UK \\ ${ }^{2}$ University of Oxford, UK
}

\begin{abstract}
In this paper, we have extended our previous study on fatigue crack closure (Tong et al, FFEMS, 2018) to examine the phenomenon of crack opening displacement (COD) and its impact on the crack tip fields in both 2D and 3D specimen geometries using full-field experimental measurements and integrated finite element modelling. Digital image correlation (DIC) and digital volume correlation (DVC) were used to measure the near-tip material responses on the surfaces (DIC) and the interior (DVC) of the specimens. Materials with elastic-plastic and large plastic characteristics were chosen for the study, where plasticity-induced premature contact between the crack flanks is known to occur. Displacement maps around the cracks were obtained using DIC and DVC at selected load increments, and were introduced as boundary conditions into the finite element (FE) models to obtain the "effective" crack driving force in terms of J-integral, and the results were compared with those "nominal" from the standard FE analysis. Both visual observation and compliance curves were used to determine the "crack opening" levels; whilst the impacts of the crack opening on the crack driving force $J$ and the normal strains ahead of the crack tip were evaluated in $2 D$ and 3D. The results from the study indicate that, crack closure, although clearly identifiable in the compliance curves, does not appear to impact on global crack driving force, such as J-integral, or strains ahead of the crack tip, hence it may well be a misconception.
\end{abstract}

Keywords: Crack closure; COD; DIC; DVC; fatigue crack; J-integral; strain

\section{INTRODUCTION}

It has been generally accepted that the use of an elastic stress intensity factor range, ${ }^{1,2} \Delta \mathrm{K}$, is adequate in correlating fatigue crack growth in most of the engineering applications under small scale yielding (SSY) conditions. For more complex loading scenarios, such as overloads or spectrum loadings, ${ }^{3}$ fatigue crack closure ${ }^{4}$ has been used to rationalise the fatigue crack growth behaviour. The concept of crack closure has prompted extensive research since Elber, ${ }^{4}$ with an estimated some 10,000 papers published on the topic. ${ }^{5}$ In particular, plasticity-induced crack closure has been used as the default interpretation of load ratio effects, and is incorporated in some of the fatigue life prediction models. Although the change in the compliance recorded behind the crack tip during loading/unloading has been captured, its impact on the crack tip fields has not been interrogated due to the lack of tools till very recently, when techniques such as DIC and DVC become more widely available for full-field measurements. ${ }^{6-22}$

The use of DIC to evaluate microscale displacements and strains near a fatigue crack tip was first reported by Sutton et al. ${ }^{6}$ Crack opening was found to be dependent of the location measured, 
and a higher value of $P_{o p} / P_{\max }$ was obtained closer to the crack tip than that further away from the crack tip. Carroll et al ${ }^{7}$ used the DIC method to examine crack opening in both macro and micro scales at three stress intensity factor ranges in a Titanium alloy. Their results also show that crack opening $\mathrm{P}_{\mathrm{op}} / \mathrm{P}_{\max }$ varies with the location of the measurement gauge, load level and the measurement resolution. Crack opening load increases with the reduction of the distance to the crack tip; decreases with the reduction of the measurement magnification. Lopez-Crespo et $a^{8}{ }^{8}$ identified crack closure under mixed mode I and II loading conditions by fitting the stress intensity factors using the displacements obtained from DIC, and the effects were attributed to combined effects of plasticity, roughness and frictional forces. The same trend was observed by $\mathrm{O}^{\prime}$ Connor et $\mathrm{al}^{1,}{ }^{18}$ who conducted both macro and micro DIC analysis of the near-tip displacements and strains using an aluminum alloy. Numerical simulation of crack closure has been carried out from the $80 \mathrm{~s}^{3,5}$ to recent days, ${ }^{23}$ with crack opening/closing loads identified and compared with the experimental results.

The three-dimensional aspects of crack closure have been studied by a number of researchers using X-ray computed tomography (XCT) and DVC. ${ }^{11-16,20} \mathrm{~A}$ key difference between the analysis using DIC or DVC is that in the former, surface patterns may be generated using artificial methods whilst in the latter, inherent microstructural features must offer sufficient spatial resolution for crack morphology identification and image correlation. Limodin et al. ${ }^{11,12}$ measured 3D fatigue crack morphologies using X-ray tomography and displacement fields of nodular cast iron using in situ loading and DVC. The stress intensity factor $\mathrm{K}$ was extracted from the displacements measured and correlated with the crack growth rates. Rannou et al. ${ }^{13}$ measured crack opening for cast iron using an enriched DVC concept to detect the crack fronts and the displacement fields, from which extended FE was used to extract the stress intensity factor. Mostafavi et al. ${ }^{16}$ and Barhli et al. ${ }^{20}$ investigated polygranular graphite using XCT and DVC techniques, where crack morphologies and opening displacements were obtained, from the latter J-integral was extracted using an integrated FE analysis. The effects of overloads on crack closure have been studied ${ }^{14,15}$ by measuring the crack opening displacements both on the surface and in the interior of the specimens.

Almost all of the published works, however, have been focused on the determination of crack opening displacements (CODs), from which crack closure was assumed and an effective $\mathrm{K}$ obtained. Recently, we revisited the crack closure phenomenon ${ }^{22}$ by examining events both behind and ahead of the crack tip as well as the crack driving force $\mathrm{K}$, using full-field deformation captured by DIC. Although the relationships between the crack opening level and the distance to the crack, load level and spatial resolution are consistent with those reported, ${ }^{6-9}$ we found that the "knees" identified in the compliance curves do not appear to correlate with the changes in the fitted $\mathrm{K}$ from the displacement data or the development of the near-tip strains. The lack of correlation spurred us to 
investigate further and ask the question: Does crack closure, as indicated by COD, really impact on the events ahead of the crack tip or on the global crack driving force?

To this end, we have examined CODs and their impacts on the crack tip fields in both 2D and 3D specimen geometries using full-field experimental measurements, integrated FE modelling and standard FE analysis. DIC and DVC were used to measure the near-tip material responses on the surfaces and the interior of the specimens. A nodular cast iron and stainless steel $316 \mathrm{~L}$ were used to be representative of elastic-plastic and large plastic material types, where plasticity-induced premature contact between the crack flanks is known to occur. A crack driving force in terms of Jintegral was determined from the integrated as well as the standard FE analysis, together with the near-tip strain fields. Both visual observation and compliance curves were used to determine the crack opening levels; whilst the "effective" crack driving forces $J$ from the integrated FE analysis were compared with the nominal ones from the standard FE analysis in both materials. We hope that the results will go some way towards answering the question posed.

\section{EXPERIMENTAL METHODS}

\subsection{Material \& Specimen}

The DIC analysis was carried out using stainless steel 316L (SS316L), which has a yield stress of 280 $\mathrm{MPa}$, an elastic modulus of $193 \mathrm{GPa}$ and a Poisson's ratio of $0.3 .{ }^{22} \mathrm{~A}$ standard compact tension (CT) specimen (ASTM E647, Width $W=60 \mathrm{~mm}$, thickness $B=7 \mathrm{~mm}$ ) was used, with a machined notch length of $12 \mathrm{~mm}$. Prior to mechanical testing, the surface of the specimen was etched to expose the microstructure features to be used for image correlation (Figure 1(a)). An average grain size was measured as approximately $17 \mu \mathrm{m}$.

The DVC analysis was carried out on a nodular cast iron $(\mathrm{NCI})^{11,12}$ which contains spherical graphite precipitations suitable for imaging and DVC analysis. The graphite nodules are around $50 \mu \mathrm{m}$ in diameter on average (Figure 1(b)). The elastic modulus of the material is $175 \mathrm{GPa}$, the Poisson's ratio is 0.27 and the yield stress is $315 \mathrm{MPa} .{ }^{11} \mathrm{~A}$ corner notched tensile specimen, with $4.7 \times 4.7 \mathrm{~mm}^{2}$ square cross section, was used (Figure 2(a)) for in situ testing. The notch was machined to finish with a notch tip radius of approximately $145 \mu \mathrm{m}$, and it was sharpened using a razor blade to facilitate cracking under load. The top view of the cracked specimen is shown in Figure 2(b), where the approximated crack front is highlighted. DVC measurements were taken from volumes of $4.7 \times 4.7 \times$ $2.0 \mathrm{~mm}^{3}$ near the surfaces $\left(0^{\circ}\right.$ and $\left.90^{\circ}\right)$ and in the interior $\left(45^{\circ}\right)$.

\subsection{Mechanical testing \& data capture}

\subsubsection{Cyclic testing and DIC data capture}


Mechanical testing was carried out on an Instron servo-hydraulic testing machine (25kN). Pre-cracking was carried out under load-control using a load shedding scheme. The initial $\Delta K$ was $25 \mathrm{MPa} \sqrt{\mathrm{m}}$, and the load was reduced manually step-by-step according to the measured crack length. The load ratio and loading frequency were 0.1 and $10 \mathrm{~Hz}$, respectively. Crack growth was monitored by surface replicas and direct current potential drop technique. The pre-cracking was terminated when the crack length reached $6.6 \mathrm{~mm}$ from the notch tip $(\mathrm{a} / \mathrm{W}=0.31)$ and at $\Delta \mathrm{K} \approx 15 \mathrm{MPa} \sqrt{\mathrm{m}}$. The specimen surface was then polished and etched using $50 \%$ distilled water, $33 \%$ chlorhydric acid, $17 \%$ nitric acid and immerged in the etching solution for 2 minutes. Mechanical testing was subsequently carried out under cyclic load $(\mathrm{R}=0.1)$ at $\Delta \mathrm{K}=15,20,25 \mathrm{MPa} \sqrt{\mathrm{m}}$. About 100 cycles were allowed to elapse before imaging after the load was raised to the next level, and three cycles were recorded at each load level. The loading waveform was trapezoidal, with a 20 second loading/unloading and a 4 second hold at minimum and maximum loads. Within each load cycle, 21 images were collected during loading/unloading at a frequency of one image per second. Optical microscopy was used also to monitor the crack, and to verify the crack tip position. The imaging system (LAVISION GMBH) used consisted of a CCD camera ( $2456 \times 2058$ pixels) and a Schneider Kreuznach F2.850 mm lens with 100 $\mathrm{mm}$ extension tubes. No filter was used in the data processing. A spatial resolution of $0.54 \mu \mathrm{m} / \mathrm{pixel}$ was achieved. A field of view (FOV), a rectangle of $1.2 \mathrm{~mm} \times 1.1 \mathrm{~mm}$ with the crack tip in the centre, was selected for imaging in order to capture the near-tip strain data ahead and COD data behind the crack tip. A subset size of $59 \times 59$ pixels $2230 \times 30 \mu \mathrm{m}$, a step size of 14 pixels $\approx 7 \mu \mathrm{m}$ and measurement windows of $28 \times 28 \mu \mathrm{m}$ and $15 \mu \mathrm{m} \times 15 \mu \mathrm{m}$ were used to calculate the displacements and strains for the DIC analysis. The standard deviations for normal displacements are $0.03 \mu \mathrm{m}$ and $0.15 \%$ for normal strains, respectively.

\subsubsection{Cyclic testing and DVC data capture}

The $\mathrm{NCl}$ specimen (Figure 2) was tested on a servo-hydraulic $100 \mathrm{kN}$ loading rig at the 112 Beamline of the Diamond Light Source synchrotron. It was subjected to a cyclic tensile load with $P_{\min }=0.45 \mathrm{kN}$ and $\mathrm{P}_{\max }=4.50 \mathrm{kN}$, corresponding to a nominal $\mathrm{K}_{\max } \approx 20 \mathrm{MPaVm} \cdot{ }^{24}$ The experiment was conducted under load control using a sine waveform, a load ratio of $R=0.1$ and a frequency of $f=10 \mathrm{~Hz}$. X-ray computed tomography with a resolution of $3.2 \mu \mathrm{m} /$ voxel was performed at regular intervals during the experiment to identify the crack initiation and to monitor the crack growth once crack initiation was established at around cycle 75,000. After 290,000 cycles, the crack grew from the notch to a length of $1.55 \mathrm{~mm}$ on one surface $\left(0^{\circ}\right), 1.56 \mathrm{~mm}$ in the interior at $45^{\circ}$ and $1.35 \mathrm{~mm}$ on the other surface $\left(90^{\circ}\right)$. A series of volumetric tomography images was then obtained during a single load cycle from $P_{\min }$ to $P_{\max }$ at incremental steps of $0.5 \mathrm{kN}$ to study changes in the compliance during loading. DVC was performed on the volumes recorded at the selected load steps using the volume at minimum load as 
a reference. The correlation procedure was conducted in a volume of interest of approximately $3.7 \mathrm{x}$ $3.7 \times 1.6 \mathrm{~mm}^{3}$ surrounding the whole crack front using DaVis StrainMaster 10. The images were corrected for rigid body motion and a subvolume size of 32 voxels ${ }^{3}\left(102 \mu \mathrm{m}^{3}\right)$ with an overlap of $75 \%$ was applied.

\subsection{Determination of Crack opening displacement (COD)}

The 2D full-field information around the crack tip of the SS316L specimen is examined as illustrated in Figure 3(a). Tracking points were used for recording the CODs in the crack wake and normal strains ahead of the crack tip, with the position of the crack tip indicated. The tracking points were chosen to be multiples of the average grain size $(17 \mu \mathrm{m})$. The data in an area over and close to the crack wake were removed to avoid the discontinuity giving rise to non-correlation errors in the DIC analysis. The CODs were calculated based on the relative vertical displacements of $A 1 i$ and $A 2 i$ for the selected points at the selected distances to the crack tip i $\Delta(i=1,2,20$ and 29); whilst the vertical distance between $\mathrm{A} 1 \mathrm{i}$ and $\mathrm{A} 2 \mathrm{i}$ was taken as $60 \mu \mathrm{m}$, as trials show that varying this distance has negligible effects on the measured CODs. ${ }^{22}$ An area of $15 \mu \mathrm{m} \times 15 \mu \mathrm{m}$ was used as the measurement window to calculate the strains at selected tracking points i $\Delta(i=1,2,10)$. Only normal strains are presented for clarity, as they are considered most relevant to crack growth. Visual observation was also carried out to track the crack flank contact during loading and unloading. Specimen surface was polished using $\mathrm{SiC}$ papers to obtain a mirror finish in an area close to the crack tip ( $\approx 1.5 \mathrm{~mm} \times 1.5 \mathrm{~mm})$. Lighting was adjusted to obtain a good contrast of specimen surface with the crack flanks within the full field of view. Images of the crack profile were taken at the loading/unloading steps at the three load cases $\Delta \mathrm{K}=15,20$, and $25 \mathrm{MPaVm}$.

The 3D full-field information around the crack tip of the $\mathrm{NCl}$ specimen was measured at three locations in the crack wake $(A-C)$ and ahead of the crack tip (D-F), as indicated in Figure 3(b), in which the red line represents the actual crack profile. The vertical distance between the pairs of COD measurement at positions A-C is $250 \mu \mathrm{m}$ (Figure 3(b)). The displacements were averaged in a volume of interest of $32 \times 32 \times 100 \mu \mathrm{m}^{3}$. Analyses were carried out on volumes $\left(3.7 \times 1.2 \times 0.1 \mathrm{~mm}^{3}\right)$ taken near the surface $\left(0^{\circ}, 90^{\circ}\right)$ and in the interior $\left(45^{\circ}\right)$ to be representatives of the surface and the bulk responses.

\section{FINITE ELEMENT ANALYSIS}

\subsection{The material models}

\subsubsection{SS316L}


The elastic-plastic material model of SS316L from Eeten and Nilsson ${ }^{25}$ was adopted where a nonlinear combined isotropic-kinematic hardening rule was used.

The von-Mises yield criterion is expressed as:

$$
f(\sigma-\alpha)=\sqrt{\frac{3}{2}\left(S-\alpha^{d e v}\right):\left(S-\alpha^{d e v}\right)}
$$

where $\mathrm{S}$ is the deviatoric stress tensor and $\alpha^{d e v}$ is the deviatoric part of the back stress.

The isotropic hardening was described by using an exponential law as:

$$
\sigma^{0}=\sigma_{0}+Q_{\infty}\left(1-e^{-b \bar{\varepsilon} p l}\right)
$$

where $\sigma_{0}$ is the initial yield surface size, $Q_{\infty}$ and $b$ are material parameters which are calibrated by cyclic experimental data, and $\bar{\varepsilon}^{p l}$ is the equivalent plastic strain.

The equivalent plastic strain is expressed as:

$$
\bar{\varepsilon}^{p l}=\frac{1}{1-v} \sqrt{\frac{1}{2}\left[\left(\varepsilon_{1}-\varepsilon_{2}\right)^{2}+\left(\varepsilon_{2}-\varepsilon_{3}\right)^{2}+\left(\varepsilon_{3}-\varepsilon_{1}\right)^{2}\right]}
$$

The overall back stress is made up of multiple back stress components, in which the evolution of the back stress components is expressed as:

$$
\dot{\alpha}_{k}=C_{k} \dot{\bar{\varepsilon}}^{p l} \frac{1}{\sigma^{0}}(\sigma-\alpha)-\gamma_{k} \alpha_{k} \dot{\bar{\varepsilon}}^{p l}+\frac{1}{C_{k}} \alpha_{k} \dot{C}_{k}
$$

where $C_{k}$ and $\gamma_{k}$ are kinematic hardening parameters, $\dot{C}_{k}$ is the rate of change of $C_{k}$ with respect to field variables and temperature. In the present study at room temperature, $k=1$ was taken for simplicity. Five parameters, including kinematic hardening parameters $C$ and $\gamma$, initial yield stress $\sigma_{0}$ and isotropic hardening parameters $Q_{\infty}$ and $b$, are extracted from the experimental results of van Eeten and Nilsson, ${ }^{25}$ and are presented in Table 1.

\subsubsection{Nodular cast iron}

A non-linear analysis was required as SSY conditions were found to be invalid for the case of $\mathrm{NCI}$. A constitutive model ${ }^{26}$ was adopted to model the non-linear behaviour of the material with options for variable yield stress, hardening as well as flow rule under compression and tension. The model has been applied to simulate the mechanical behaviour of the ductile cast iron with variable hardening behaviour under compression and tension. ${ }^{27}$ It is assumed that the maximum principal stress governs tension yielding, while the deviatoric stresses governs the pressure-independent compression 
yielding. On a given meridional plane, the yield surface includes two distinct line segments expressed by

$$
R \sigma_{m}^{e q}-p-\sigma_{t}=0
$$

and

$$
\sigma_{m}^{e q}-\sigma_{c}=0
$$

where variable $R$, which identifies the meridional plane in principal stress space, is calculated by using

the deviatoric stress $S$ and the Mises equivalent stress $\sigma_{m}^{e q} ; p$ is the equivalent pressure stress; $\sigma_{t}$ and $\sigma_{c}$ are the yield stress under uniaxial tension and uniaxial compression, respectively. The material has a higher yield stress in compression than that in tension and a variable hardening behaviour dependent of plastic strain. By fitting hardening curves of the yield stress $\sigma_{t}\left(\sigma_{c}\right)$ vs plastic strain $\varepsilon^{p l}$ of the material ${ }^{28}$, the relationship between the tensile $\left(\sigma_{t}\right)$ and compressive $\left(\sigma_{c}\right)$ yield stress and the plastic strain $\varepsilon^{p l}$ may be expressed as:

$$
\sigma_{t}=5.77\left(\varepsilon^{p l}\right)^{3}-36.48\left(\varepsilon^{p l}\right)^{2}+88.63\left(\varepsilon^{p l}\right)+315
$$

and

$$
\sigma_{c}=2.57\left(\varepsilon^{p l}\right)^{3}-15.52\left(\varepsilon^{p l}\right)^{2}+63.89\left(\varepsilon^{p l}\right)+333
$$

By using Eqs. 7 and 8, the yield stresses $\left(\sigma_{t}, \sigma_{c}\right)$ may be obtained as a function of plastic strain.

The rate of the equivalent plastic strain is expressed as:

$$
\dot{\bar{\varepsilon}}_{t}^{p l}=\frac{1}{\sigma_{t}}\left(-p \dot{\varepsilon}_{v o l}^{p l}+\sigma_{m}^{e q} \dot{e}^{p l}\right)
$$

where the volumetric component of the plastic strain rate $\dot{\varepsilon}_{v o l}^{p l}=\dot{\varepsilon}^{p l}: \mathbf{I}, \mathbf{I}$ is the second-order identity tensor; and the deviatoric component of the plastic strain rate $\dot{e}^{p l}=\frac{2}{3} \dot{\varepsilon}^{p l}: \mathbf{n}, \mathbf{n}=\left(3 / 2 \sigma_{m}^{e q}\right) S$ is the flow direction in the deviatoric plane.

\subsection{Calculation of J-integral in the presence of crack closure}

The standard J-integral in $2 \mathrm{D}$ is defined as:

$$
J=\lim _{\Gamma \rightarrow 0} \int_{\Gamma} n \cdot H \cdot q d \Gamma
$$

where $q$ is a unit vector in the virtual crack extension direction and $n$ is the outward normal to $\Gamma . H$ is given by 


$$
H=W \mathbf{I}-\sigma \cdot \frac{\partial u}{\partial X}
$$

For elastic-plastic or elastic-viscoplastic material behavior $W$ is defined as the elastic strain energy density plus the plastic dissipation; $\mathbf{I}$ is the second-order identity tensor; $u$ is the displacement vector. The path $\Gamma$ of J-integral is chosen around the crack tip, and a converged value may be obtained for a path-independent case. ${ }^{29}$

When residual stresses due to crack closure are present, traction-free condition is violated hence the path-independency of standard J-integral no longer holds. ${ }^{30}$ Initial strains caused by residual stresses $^{31,32}$ may be introduced into the standard formula of J-integral to restore the pathindependency of J-integrals, and this method was used in the current work.

The modified path-independent J-integral expression considering initial strains in a $2 \mathrm{D} \mathrm{FE}$ model was given as: ${ }^{32}$

$$
J=\int_{\Gamma}\left(W \delta_{1 i}-\sigma_{i j} \frac{\partial u_{i}}{\partial x_{1}}\right) n_{i} d s+\int_{A} \sigma_{i j} \frac{\partial \epsilon_{i j}^{0}}{\partial x_{1}} d A
$$

Where $\int_{\Gamma}\left(W \delta_{1 i}-\sigma_{i j} \frac{\partial u_{i}}{\partial x_{1}}\right) n_{i} d s$ is the standard J-integral expression, and $\int_{A} \sigma_{i j} \frac{\partial \epsilon_{i j}^{0}}{\partial x_{1}} d A$ is the new item introduced considering the effect of initial strain on the J-integral. $\delta_{1 i}$ is Kronecker's delta; $\sigma_{i j}$ and $u_{i}$ are components of stress and displacement, respectively; $n_{i}$ is the unit vector normal to $\Gamma$ and $d s$ is the path length along $\Gamma ; x_{1}$ is the coordinate in the local crack driving direction; $\epsilon_{i j}^{0}$ is initial strain; $A$ is the area enclosed by $\Gamma$.

The detailed FE discretisation process was adopted from Lei and $\mathrm{O}^{\prime}$ Dowd. ${ }^{32}$ A post-processing program was written in the present study which reads the data from the ABAQUS.fil file, and the modified path-independent J-integral (Eq 12) was then calculated.

\subsection{Integrated and standard FE analysis}

A 2D FE model (Figure 4(a)) was created for the same geometry of the SS316L specimen as used in the experiment. To prevent hourglass mode and shear locking during the FE analysis, a 4-noded plane stress bilinear element (CPS4) with enhanced hourglass control and reduced integration (ABAQUS ${ }^{26}$ ) was applied to mesh the model, and the total numbers of nodes and elements in the model are 12,922 and 12,768 , respectively. Refined meshes were applied to the near tip region, so the large strain gradients near the crack tip may be captured more accurately. Contact pairs were defined between the crack flanks to prevent potential crack penetration due to crack closure under fatigue loading. No slip was assumed between the CT specimen and the loading pin, and the cyclic loading was applied 
through the centres of the loading pins. To model the residual plastic strain in the CT specimen due to pre-cracking, crack growth was simulated by releasing sequential crack tip nodes under cyclic loading. To avoid a sudden change of the measured displacement, ${ }^{33}$ one node was released at the minimum stress for every two cycles. A sharp crack was introduced in the FE model and the crack blunting post pre-cracking was neglected.

A volume $(4.7 \times 4.7 \times 1 \mathrm{~mm})$ of the $\mathrm{NCl}$ specimen used in the experiment (Figure 2(a)) was modelled in the 3D FE simulation. A quarter circular crack profile was created in the crack plane. To prevent both hourglass mode and shear locking during the FE analysis, 8-nodded linear brick elements with reduced integration and enhanced hourglass control were used to mesh the 3D FE model (Figure 4(b)). The same basic material properties as those used in the experiment were used in the FE analysis.

The displacement fields measured from DIC/DVC were imported to the 2D/3D FE models as boundary conditions to obtain the "effective" J-integrals. To reduce the potential errors to interpolate the DIC/DVC displacement fields to the nodes of the FE mesh, the nodal spacings of the FE meshes were chosen to match the DIC/DVC grid sizes so that the two grids between the DIC/DVC and the FE model are consistently registered. The mesh in the DIC region around the crack tip for the 2D SS316L FE model was refined to the DIC grid size of $7.74 \mu \mathrm{m}$; whilst the mesh in the 3D cast iron FE model was refined to the DVC grid size of around $50 \mu \mathrm{m}$. The influence of the mesh size was examined by using two element sizes, i.e. $5 \mu \mathrm{m}$ and $7.74 \mu \mathrm{m}$ for the 2D SS316L; and $30 \mu \mathrm{m}$ and $50 \mu \mathrm{m}$ for the 3D cast iron. The results show consistent stress-strain responses around the crack tip in the distances of interest for COD and strain measurements. Data in a region close to the crack wakes (Figure 4(a)) were excluded to reduce the noise due to non-correlation errors in the DIC anaylsis. ${ }^{34}$ Similarly, DVC data within a quarter circular volume with a cross section of $2.7 \mathrm{~mm} \times 0.4 \mathrm{~mm}$ around the 3D crack flanks were also excluded (Figure 4(b)) for the same reason.

Standard FE analyses were also carried out using the loads from the experiments for both SS316L and NCl specimens. In the case of the former, the loads were applied incrementally through the pins to obtain the "nominal" J-integrals for the three load cases $\Delta K=15,20$, and $25 \mathrm{MPaVm}$. In the case of latter, to reduce the computational costs, 2D plane stress and plane strain models were created to represent the surface and interior responses. The initial fatigue crack growth in the experiment was simulated in the FE analysis, similarly to that in the case of SS316L, where contact pair's definition was assumed on the crack flanks and node-releasing method used to simulate the crack growth. Refined meshes of a size about $10 \mu \mathrm{m}$ were used around the crack tip and nominal stresses were applied based on the $K$ calibration of a corner $\operatorname{crack}^{35}$ (Figure 4(c)). The constitutive model (3.1.2) was applied in the 2D FE simulations under two load cases of $K_{1}$ (19 MPaVm for plane 
stress (surface) and $16 \mathrm{MPaVm}$ for plane strain (interior) and $\mathrm{K}_{2}$ (38 MPaVm for plane stress and 31 $\mathrm{MPaVm}$ for plane strain). The differences in the nominal $\mathrm{K}$ values are due to the variation of the crack length around the crack front found in the experiment; whilst the second load case was used to facilitate the discussion.

\section{RESULTS}

\subsection{D ANALYSIS}

\subsubsection{Crack opening measured by COD}

Figure 5 shows the compliance curves at the selected distances to the crack tip $(1,2,20,29 \Delta ; \Delta=17$ $\mu \mathrm{m})$ at the three nominal $\Delta \mathrm{K}$ levels from both the DIC measurements and the FE simulations. The results seem to be similar between the DIC and the FE; and closer to crack tip $(1,2 \Delta)$ as opposed to away from the crack tip $(20,29 \Delta)$. Significant crack closure, as identified by the change of slope in the $\mathrm{P} / \mathrm{P}_{\max }$ vs COD curves, or a "knee", is evident in all cases but particularly at low $\Delta \mathrm{K}(15 \mathrm{MPaVm})$ and at positions away from the crack tip $(20,29 \Delta)$, although the level of closure appears to reduce progressively as $\Delta \mathrm{K}$ increases. The results are consistent with those from the literature. ${ }^{6,7,22}$

\subsubsection{Crack opening profile}

Physical closure of the crack flanks was monitored using optical method during loading and unloading. Figure 6 shows the visual observation recorded for the three load cases during loading (unloading results are similar, omitted here). These records show clearly that the opening of a crack starts from behind the crack tip and progresses towards the crack tip as the load increases, but the full opening of the crack appears to be much later, particularly at the low $\Delta K(15 \mathrm{MPaVm})$ when the full opening of the crack does not appear to occur till the peak load is approached. Finite element analysis shows a similar trend, with progressive crack opening from behind the crack tip towards the crack tip.

In Figure 7, a summary of the "opening" loads as identified from the CODs (Figure 5) and from visual observation (Figure 6) and the corresponding FE results are presented for the three load cases. Consistent with previous reports, ${ }^{6-9,22}$ the opening loads measured appear to increase as the distance to the crack tip decreases, but more significantly, the measurements from the compliance curves differ considerably from those from visual observations in all cases, but particularly at higher load levels.

\subsubsection{Normal strains ahead of the crack tip}

The measured normal strains ahead of the crack tip are shown in Figure 8 during loading (similar results were obtained for unloading, omitted) under $\Delta \mathrm{K}=15,20,25 \mathrm{MPaVm}$, at the selected distances to the crack tip $(1,2$ and $10 \Delta, \Delta=17 \mu \mathrm{m})$. Although there are significant scatters away from the crack 
tip, particularly at low $\Delta K$, a trend of increasing normal strains with the increase of load is evident, particularly close to the crack tip (1-2 grain sizes). There appears to be no apparent "knee", as identified from the compliance trace during loading or unloading from either the DIC or the FE results, suggesting effective load transfer to the near-tip strain field and no stress "shielding" effects due to the progressive crack closure of crack flanks observed (Figure 6) or measured from the compliance curves (Figure 5).

\subsubsection{Crack driving force J-integral}

As SSY is invalid for all the cases studied in SS316L (the ratios of the crack length over the plastic zone size are less than 50), the material constitutive model (3.1.1) was used for the integrated and standard FE analysis. The "effective" J-integrals were calculated from the integrated FE model as a function of load for the three load cases studied. To reduce the measurement errors, the DIC data in a region along the crack flank were excluded (See Figure 4(a)). The "nominal" J-integrals were also calculated using the standard FE analysis under load control for the three load cases, and the results are shown in Figure 9. It is evident that for almost all the cases the "effective" J-integrals are very close to the nominal J-integrals, and there is no evidence of any "attenuation" due to the observed progressive contacts between the crack flanks (Figure 6) or the change of the stiffness (Figure 5). The results indicate that, even with large plastic deformation, the premature contact between the crack flanks does not appear to have any impact on the crack driving force as represented by the J-integral. Another parameter, crack tip opening displacement (CTOD) was also examined and found to be correlated with the J-integral and the trend with the applied load is also similar (omitted here for clarity).

\subsection{D ANALYSIS}

\subsubsection{Crack opening measured by COD}

The compliance curves were measured by the experiments and by the FE simulations at the three selected points (Figure 3(b)) along the crack wake and are presented in Figure 10 for the load case $K_{1}$. The numerical results include $\mathrm{FE}_{\mathrm{Dvc}}$ from the integrated $\mathrm{FE}$ model (Figure $4(\mathrm{~b})$ ) and $\mathrm{FE}_{\mathrm{K} 1}$ from the standard FE analysis (Figure 4(c)); whilst the experimental results are from the DVC measurements. Generally, the three sets of data compare well, with the results from the surface slightly higher than those from the interior, with a value of COD about $3.0 \mu \mathrm{m}$ at the surface $\left(0^{\circ}\right)$ as opposed to $2.2 \mu \mathrm{m}$ in the interior $\left(45^{\circ}\right)$ at point $D$ under the maximum load from the DVC measurement, although there appears to be little difference between the behaviour on the surfaces and that in the interior. Essentially linear relationships appear to be dominant in all cases, till some deviations from a linear 
relation between $P / P_{\max }$ and COD at higher loads, with a slope change occurred around $P / P_{\max } \approx 0.8$ $(B, C)$, both on the surfaces and in the interior. It is doubtful, however, this deviation has anything to do with "crack opening", as essentially linear behaviour seems to be dominant during the process of loading.

\subsubsection{Normal strains ahead of the crack tip}

Figure 11 shows the normal strains ahead of the crack tip on the surfaces $\left(0^{\circ}, 90^{\circ}\right)$ and in the bulk $\left(45^{\circ}\right)$ as a function of applied load. No change in the slopes is evident for almost all cases, except some slight deviations at high loads $\left(>80 \% \mathrm{P}_{\max }\right)$ from an apparent linear relationship between the normal strain and applied load at the point close to the crack tip (D) on the surfaces $(a, c)$, but not in the interior (b), where larger scatters appear to be present than those near the surfaces, a limitation perhaps of the measurement method.

\subsubsection{Crack driving force J-integral}

The non-linear material model (3.1.2) was used in the integrated 3D FE analysis (Figure 4(b)), from which the "effective" J-integrals were obtained on the surfaces and in the interior using the displacements obtained from the DVC. Nominal J-integrals were also obtained by the standard FE analysis using the 2D FE models (Figure 4(c)), and the results are presented in Figure 12. It is evident that, the effective and the nominal J-integrals are very close on the surface, and are reasonably close in the interior. In both cases, there is lack of evidence of attenuation in the effective crack driving force. In fact, the effective J-integral appears to be slightly higher than the nominal one, but this is more likely due to the 2D simplification of plane stress state in the standard FE analysis.

\section{DISCUSSION}

For a topic that has probably generated the greatest interest in the fatigue research community since Elber, ${ }^{4}$ the concept of fatigue crack closure has intrigued researchers for decades. Elaborate methods have been developed to measure crack closure due to a number of physical mechanisms, mainly of plasticity-induced, roughness-induced or oxide-induced crack closures; whilst numerous models have been developed to predict the "effective" crack driving force for fatigue crack propagation. ${ }^{5}$ The experimental evidence accumulated over the decades shows with little doubt that premature contact does occur between the crack flanks in ductile metallic materials, which may be captured by a number of methods but typically by compliance traces. More recent evidence ${ }^{6,7,18,22}$ from full-field studies further reveals the complex nature of the phenomenon, in that the measured "opening" load varies with the measurement location, ${ }^{6,7,18}$ load level, ${ }^{7,22}$ and measurement resolution. ${ }^{7,8,22}$ In this regard, the present results are consistent with those from the literature. 
But does the measured "knee" from the compliance curves indicate physical crack closure? Our observation, using both optical microscopy and FE simulation, appears to suggest a progressive process that starts from behind the crack tip and ends at the crack tip towards the peak load during loading, there appears to be no correlation between the load level identified as "opening" by the compliance method and the behaviour of the crack flanks (Figure 7). Admittedly, allowance should be made of the limitations in the resolution of the optical microscopy and of the FE simulation, but the evidence so far appears to confirm the lack of correlation between the "knee" identified from the compliance traces and the physical crack closure.

Central to our enquiry is if the measured "crack opening" impacts on the events ahead of the crack tip or the crack driving force, a topic not possible to explore till more recently, when high resolution full-field measurement tools become more readily available. Full-field high resolution measurements using DIC and DVC afford a new opportunity of interrogation of crack tip fields without necessarily discriminating the underline physical mechanisms or microstructural characteristics. This apparent weakness has the advantage of simplifying the matter, and is entirely appropriate for a continuum mechanics approach to the characterisation of fatigue crack growth behaviour. With an integrated FE analysis, where the displacements from the experimental measurements are injected into the FE models, further analysis may be carried out to obtain the strains ahead of the crack tip and the "effective" crack driving forces such as $\mathrm{K}$ and J for the actual test cases. The feedback from the experimental full-field measurements also allows "fine tuning" of the materials parameters used in the FE models, if necessary, hence improving the overall accuracy of the model predictions using such an integrated approach.

The most significant discovery of the present full-field study is the lack of correlations between the "crack closure" measured in the crack wake and the normal strains ahead of the crack tip and the effective crack driving force J-integral. The latter is confirmed, for the first time, using the integrated and the standard FE analyses where the effective and the nominal J-integrals are shown to be similar (Figure 9 and Figure 12). Conclusive evidence in the case of SS316L shows that, in the presence of significant plastic deformation and crack closure from both compliance curves and visual observation, the crack driving force in terms of J-integral is unaffected for the load cases examined. In the case of nodular cast iron, the extent of non-linear deformation is relatively limited, although the results are not inconsistent with those of SS316L. We envisage that more pronounced non-linear deformation at higher load will lead to more evidence of crack closure from compliance traces. For illustration purposes, a higher load case $\left(K_{2}\right)$ was examined where the load was doubled. Figure 13 shows the behaviour of CODs for both cases for the $\mathrm{NCl}$ specimen. As expected, pronounced closure behaviour, i.e., a "knee" at about $\mathrm{P} / \mathrm{P}_{\max } \approx 0.6-0.7$ under the higher load, is predicted both on the surface and in 
the interior. The crack driving force in terms of J-integral, however, does not appear to be affected by the change, increases continuously with load, consistent in trend with those observed in SS316L.

We measured the normal strains to examine a concept of strain ratchetting ${ }^{36}$ as a potential physical crack driving force, but there seem no reason other parameters near a crack tip could not be explored in the characterisation of fatigue cracks using full-field tools. Stainless Steel $316 \mathrm{~L}$ is a model material with significant plasticity and well defined material model; whilst nodular cast iron has good microstructural features that allow DVC analysis following micro-tomography imaging, although its non-linear behaviour seems to be more confined at the level of the applied load. Nevertheless, there seems little difference in the material response on the surfaces and in the interior, which seems to favour the use of DIC, where data may be collected on the surfaces only. Future work on more 3D geometries and other ductile materials may shed further light on the topic, hopefully answer the question more comprehensively. ${ }^{37}$

\section{CONCLUSION}

The results from the present study indicate that, crack closure, although clearly identifiable in the compliance curves in the presence of significant plasticity, does not appear to impact on global crack driving force, such as J-integral, or strains ahead of the crack tip, hence it may well be a misconception which warrants further studies.

\section{REFERENCES}

1. Paris PC, Gomez MP, Anderson WE. A rational analytic theory of fatigue. Trend Eng. 1961; 13:914.

2. Rice JR. Mechanics of Crack Tip Deformation and Extension by Fatigue. Fatigue Crack Propagation. 1967; ASTM STP 4:247-309.

3. Newman Jr JC. Mechanics of fatigue crack closure, ASTM STP768. Philadelphia (Pennsylvania): American Society for Testing and Materials; 1981.

4. Elber W. Fatigue Crack Closure Under Cyclic Tension. Eng Fract Mech. 1970; 2:37-45.

5. Pippan R, Hohenwarter A. Fatigue crack closure: a review of the physical phenomena. Fatigue Fract Eng Mater Struct. 2017; 40:471-95.

6. Sutton MA, Orteu JJ, Schreier H. Image correlation for shape, motion and deformation measurements: Basic concepts, theory and applications. Springer US, 2009. 
7. Carroll J, Efstathiou C, Lambros J, Sehitoglu H, Hauber B, Spottswood S, et al. Investigation of fatigue crack closure using multiscale image correlation experiments. Eng Fract Mech. 2009; 76:238498.

8. Lopez-Crespo P, Shterenlikht A, Yates JR, Patterson EA, Withers PJ. Some experimental observations on crack closure and crack-tip plasticity. Fatigue Fract Eng Mater Struct 2009;32:418-29.

9. Leser WP, Carolina N, Carolina N, Newman JA, Johnston WM. Fatigue crack closure analysis using digital image correlation. Nasa/Tm-2010-216695. 2010.

10. Yates JR, Zanganeh M, Tai YH. Quantifying crack tip displacement fields with DIC. Eng Fract Mech. 2010; 77:2063-76.

11. Limodin N, Réthoré J, Buffière JY, Gravouil A, Hild F, Roux S. Crack closure and stress intensity factor measurements in nodular graphite cast iron using three-dimensional correlation of laboratory X-ray microtomography images. Acta Mater. 2009;57(14):4090-4101. doi:10.1016/j.actamat.2009.05.005.

12. Limodin N, Réthoré J, Buffière JY, et al. Influence of closure on the 3D propagation of fatigue cracks in a nodular cast iron investigated by X-ray tomography and 3D volume correlation. Acta Mater. 2010;58(8):2957-2967. doi:10.1016/j.actamat.2010.01.024.

13. Rannou J, Limodin N, Réthoré J, et al. Three dimensional experimental and numerical multiscale analysis of a fatigue crack. Comput Methods App/ Mech Eng. 2010;199(21-22):1307-1325. doi:10.1016/j.cma.2009.09.013.

14. Yusof F, Lopez-Crespo P, Withers PJ. Effect of overload on crack closure in thick and thin specimens via digital image correlation. Int J Fatigue. 2013;56:17-24. doi:10.1016/j.ijfatigue.2013.07.002.

15. Lopez-Crespo P, Withers PJ, Yusof F, et al. Overload effects on fatigue cracka-tip fields under plane stress conditions: Surface and bulk analysis. Fatigue Fract Eng Mater Struct. 2013;36(1):75-84. doi:10.1111/j.1460-2695.2012.01670.x.

16. Mostafavi M, McDonald SA, Mummery PM, Marrow TJ. Observation and quantification of threedimensional crack propagation in poly-granular graphite. Eng Fract Mech. 2013;110:410-420. doi:10.1016/j.engfracmech.2012.11.023.

17 Rabbolini S, Beretta S, Foletti S, Cristea ME. Crack closure effects during low cycle fatigue propagation in line pipe steel: An analysis with digital image correlation. Eng Fract Mech. 
2015;148:441-456.

18. O'Connor SJ, Nowell D, Dragnevski KI. Measurement of fatigue crack deformation on the macroand micro-scale: Uniform and non-uniform loading. Int J Fatigue. 2016; 89:66-76.

19. Hos Y, Freire JLF, Vormwald M. Measurements of strain fields around crack tip under proportional and non-proportional mixed-mode fatigue loading. Int J Fatigue 2016; 89:87-98.

20. Barhli SM, Saucedo-Mora L, Jordan MSL, et al. Synchrotron X-ray characterization of crack strain fields in polygranular graphite. Carbon N Y. 2017;124:357-371. doi:10.1016/j.carbon.2017.08.075.

21. Gonzales GLG, Gonzalez JAO, Castro JTP, Freire JLF. A J-integral approach using digital image correlation for valuating stress intensity factors in fatigue cracks with closure effects. Theo Appl Fract Mech. 2017; 90:14-21.

22. Tong J, Alshammrei S, Wigger T, Lupton C, Yates JR. Full-field characterization of a fatigue crack: Crack closure revisited. Fatigue Fract Eng Mater Struct. 2018; 141:2130-2139.

23. Espinosa AAA, Fellows NA, Durodola JF, Fellows LJ. Development of numerical model for the determination of crack opening and closure loads, for long cracks. Fatigue Fract. Eng. Mater. Struct., 2017;40:571-585.

24. Zhao LG, Tong J, Byrne J. Stress intensity factor $\mathrm{K}$ and the elastic T-stress for corner cracks. Int J Fracture 2001; 109:209-225.

25. van Eeten P, Nilsson F. Constant and variable amplitude cyclic plasticity in $316 \mathrm{~L}$ stainless steel. J Test Eval. 2006; 34:298-311.

26. ABAQUS Version 6.14, User's manual, Inc. and Dassault systems; 2014.

27. Spiteri $\mathrm{P}$, Ho S, Lee YL. Assessment of bending fatigue limit for crankshaft sections with inclusion of residual stresses. Int J Fatigue. 2007; 29:318-329.

28. Adrien J. Optimisation des cycles thermiques appliqués aux fontes G.S. ferritiques vis à vis des propriétés de fatigue. PhD thesis. Institut National des Sciences Applique'es de Lyon, Ge'nie des Mate'riaux, Villeurbanne; 2004.

29. Rice JR. A path independent integral and approximate analysis of strain concentration by notches and cracks. J Appl Mech. 1968;35:379-86.

30. Mirzaee-Sisan A, Truman CE, Smith DJ, Smith MC. Interaction of residual stress with mechanical loading in a ferritic steel. Eng Fract Mech. 2007; 74:2864-80. 
31. Lee $\mathrm{CH}$, Chang KH. Finite element computation of fatigue growth rates for mode I cracks subjected to welding residual stresses. Eng Fract Mech. 2011; 78:2505-20.

32. Lei Y, O'Dowd NP. Fracture mechanics analysis of a crack in a residual stress field. Int J Fract. 2000; 106:195-216.

33. de Matos PFP, Nowell D. On the accurate assessment of crack opening and closing stresses in plasticity-induced fatigue crack closure problems. Eng Fract Mech. 2007; 74:1579-1601.

34. Barhli SM, Mostafavi M, Cinar AF, Hollis D, Marrow TJ. J-integral calculation by finite element processing of measured full-field surface displacements. Exp Mech. 2017; 57:997-1009.

35. Pickard AC. The application of 3-dimensional finite element methods to fracture mechanics and fatigue life prediction. EMAS, London; 1986.

36. Zhao LG, Tong J. A viscoplastic study of crack-tip deformation and crack growth in a nickel-based superalloy at elevated temperature. J Mech Phys Solids. 2008; 56:3363-3378.

37. Tong J. Full-field characterisation of crack tip deformation and fatigue crack growth using digital image correlation-a review. Fatigue Fract. Eng. Mater. Struct., 2018;41:1855-1869. 


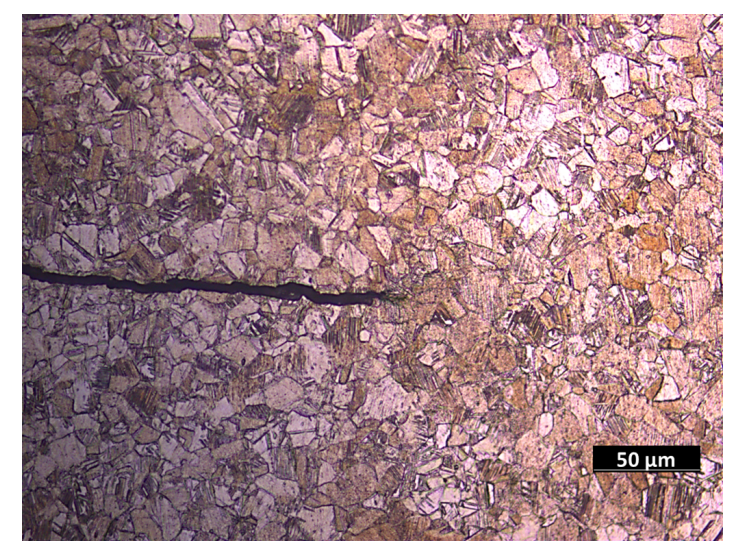

(a)

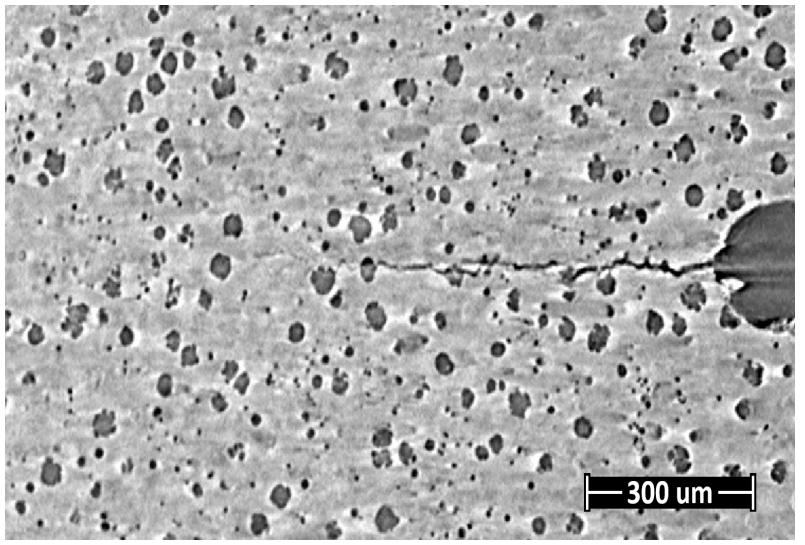

(b)

Figure 1(a). A typical etched surface of the SS316L specimen used for the DIC analysis; (b) microstructural details of the nodular cast iron used for the DVC analysis.

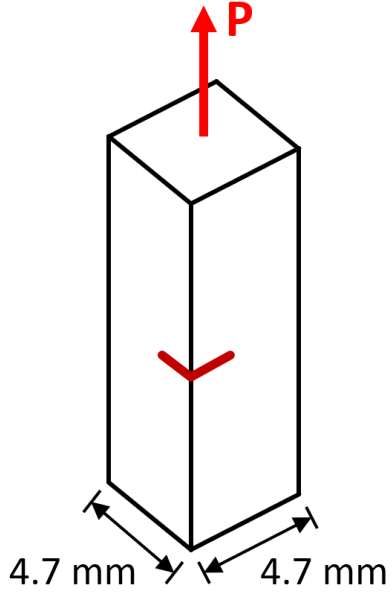

(a)

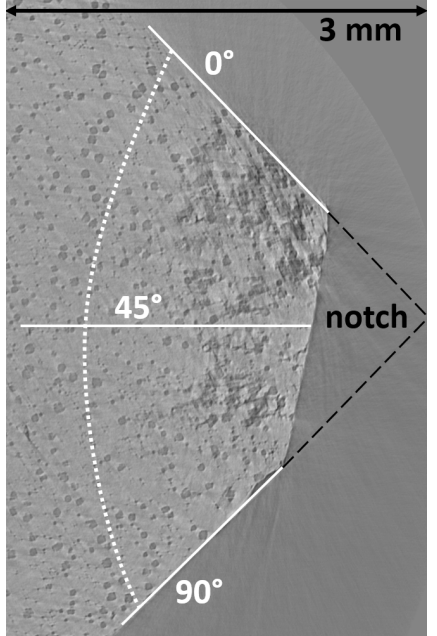

(b)

Figure 2(a). A schematic of the nodular cast iron specimen geometry with the notch (red) indicated; (b) the top view of a section of the specimen showing the notched corner from which a crack is formed. The approximated crack front is highlighted as a dotted white line. The DVC measurements were taken from volumes $\left(3.7 \times 3.7 \times 1.6 \mathrm{~mm}^{3}\right)$ near the surfaces $\left(0^{\circ}\right.$ and $\left.90^{\circ}\right)$ and in the interior $\left(45^{\circ}\right)$. 


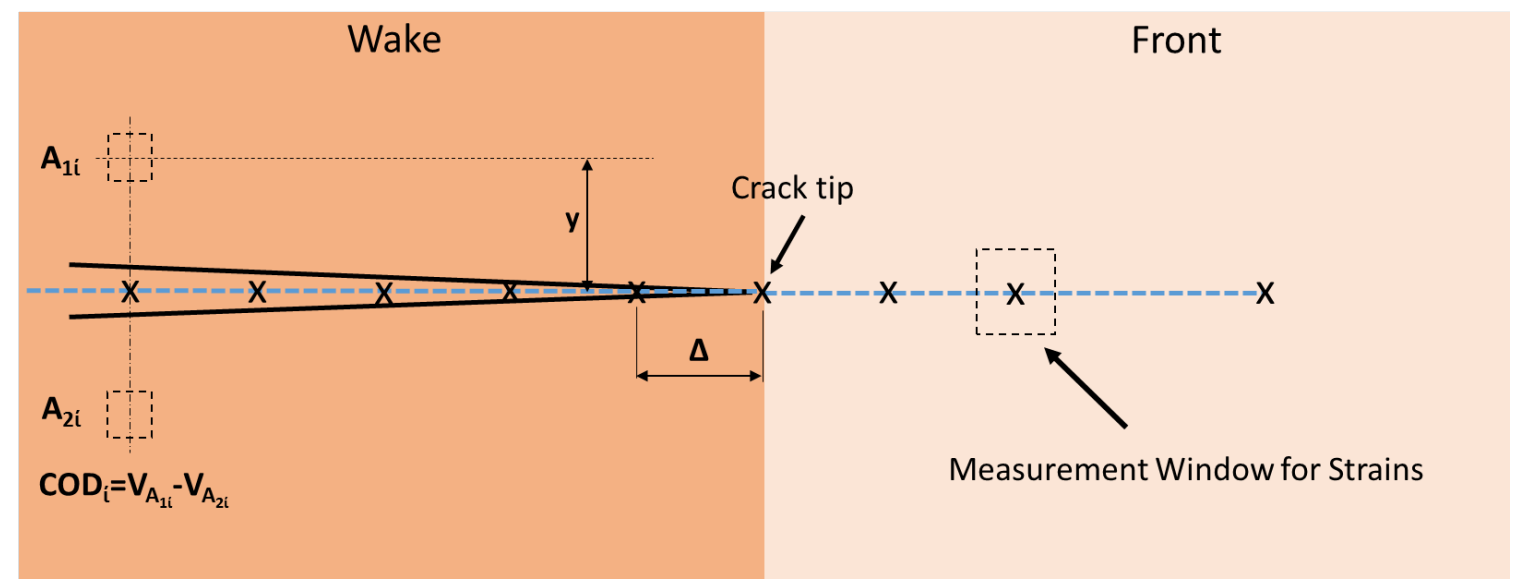

Figure 3(a). An illustration of the tracking points used for recording the normal strains ahead of the crack tip (Front: $i \Delta, i=1,2,10$ ) and the CODs in the crack wake (Wake: $i \Delta, i=1,2,20,29)$ in the DIC analysis. The tracking points were chosen to be multiples of the average grain size $(\Delta=17 \mu \mathrm{m})$. The CODs were calculated from the vertical displacements of $A 1 \mathrm{i}$ and $\mathrm{A} 2 \mathrm{i}$ at a fixed distance to the crack plane y $(30 \mu \mathrm{m})$; the measurement window for strain calculation was $15 \mu \mathrm{m} \times 15 \mu \mathrm{m}$.

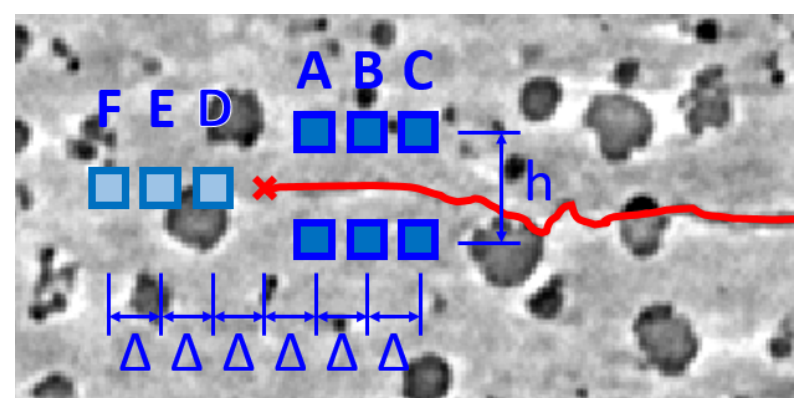

Figure $3(b)$. An illustration of the tracking points used for $\operatorname{COD}(A-C)$ and strain (D-F) measurements in the DVC analysis $\left(\Delta=80 \mu \mathrm{m}, \mathrm{h}=250 \mu \mathrm{m}, \mathrm{AOI}=32 \times 32 \times 100 \mu \mathrm{m}^{3}\right)$. 


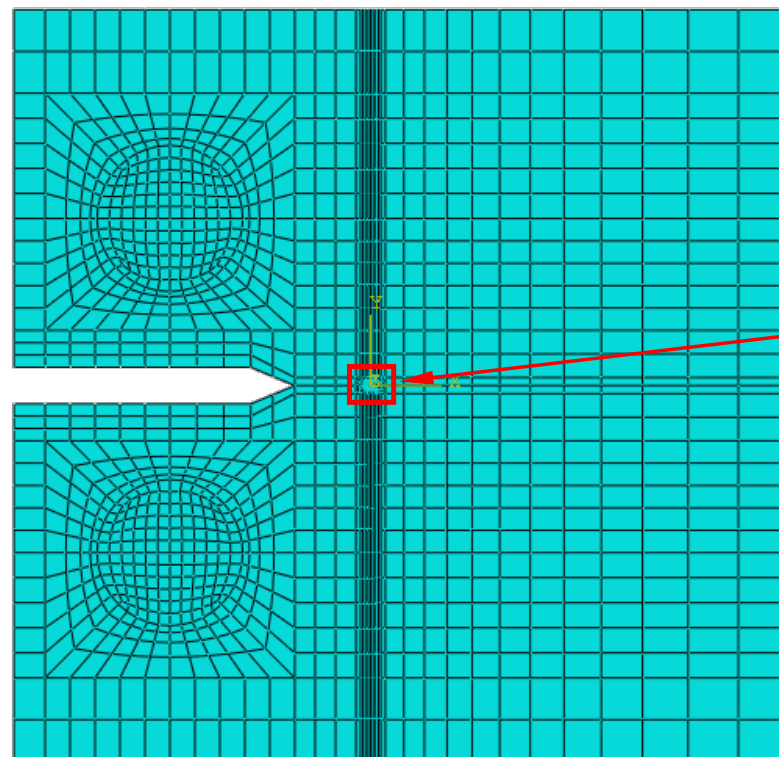

DIC displacements applied the FE nodes

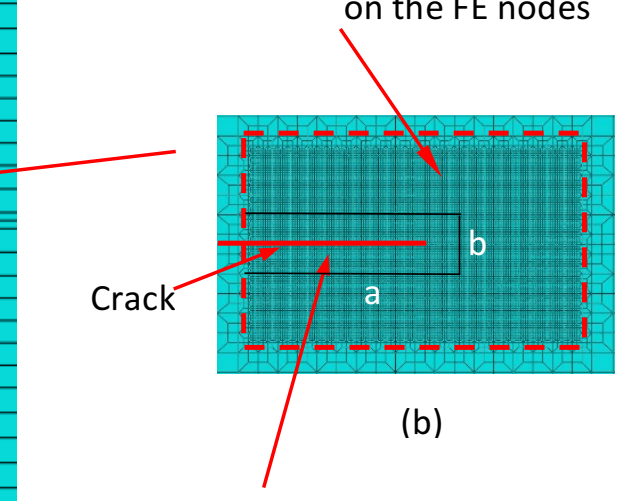

Region with DIC data excluded $(\mathrm{a} \times \mathrm{b}=0.65 \mathrm{~mm} \times 0.1 \mathrm{~mm})$

(a)

Figure 4(a). The finite element model of the CT specimen used for the analyses, with the displacements extracted from the DIC analysis as the boundary conditions (effective) and under load control (nominal). A region with the DIC data excluded is marked $(a \times b)$ to reduce the correlation scatter.

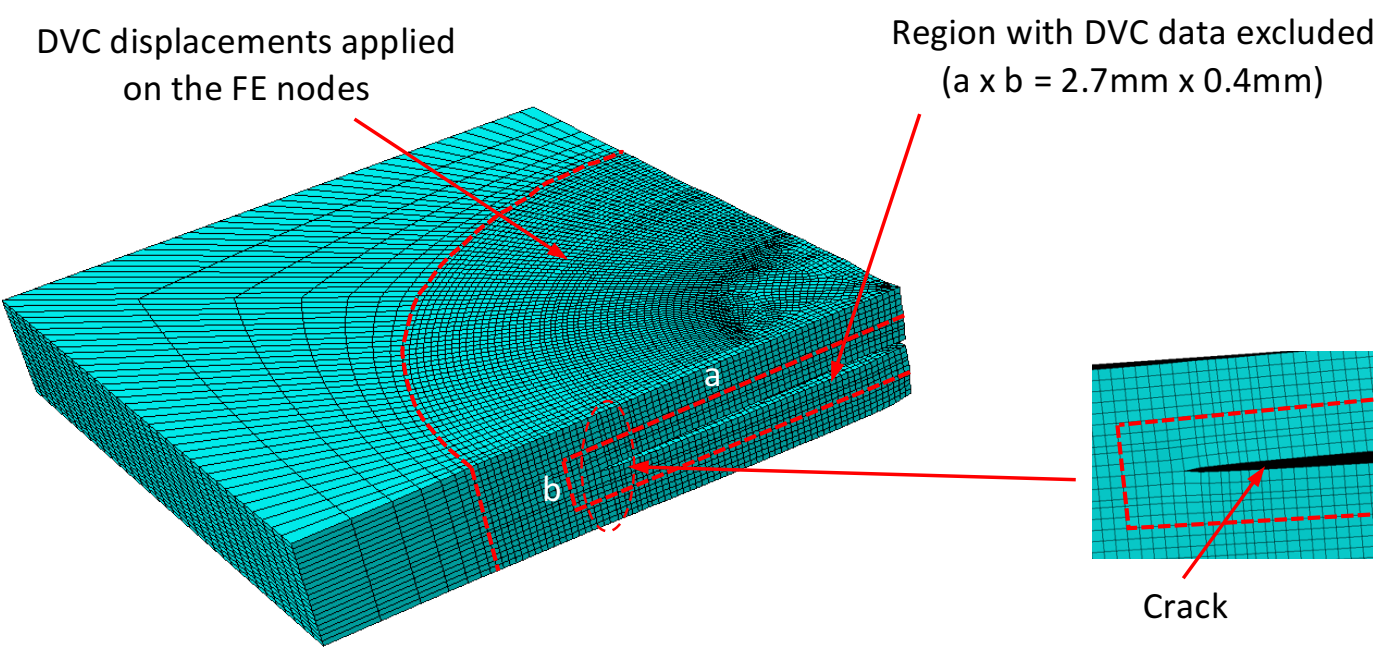

Figure 4(b). The finite element model of the nodular cast iron used for the effective FE analysis, where the displacements extracted from the DVC analysis were used as the boundary conditions. The DVC data in a quarter circular volume with a cross-section $(a \times b)$ were excluded to reduce the correlation scatter. 


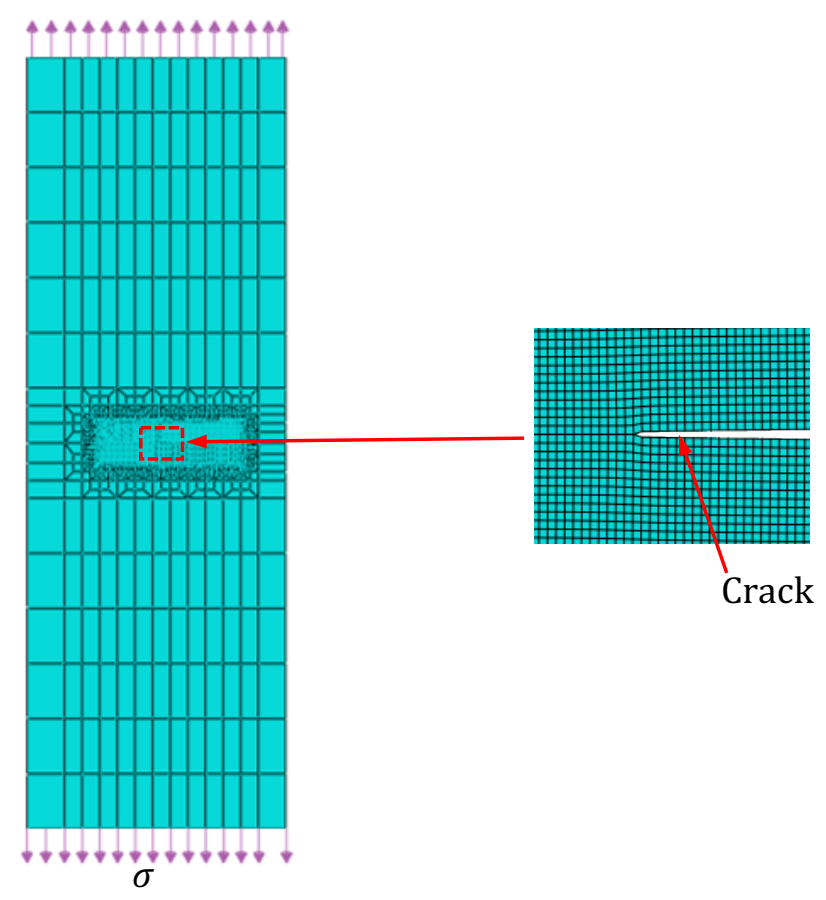

Figure 4(c). The finite element model of the nodular cast iron used for the standard FE analysis, with plane stress (surface) and plane strain (interior) conditions assumed under stress control.

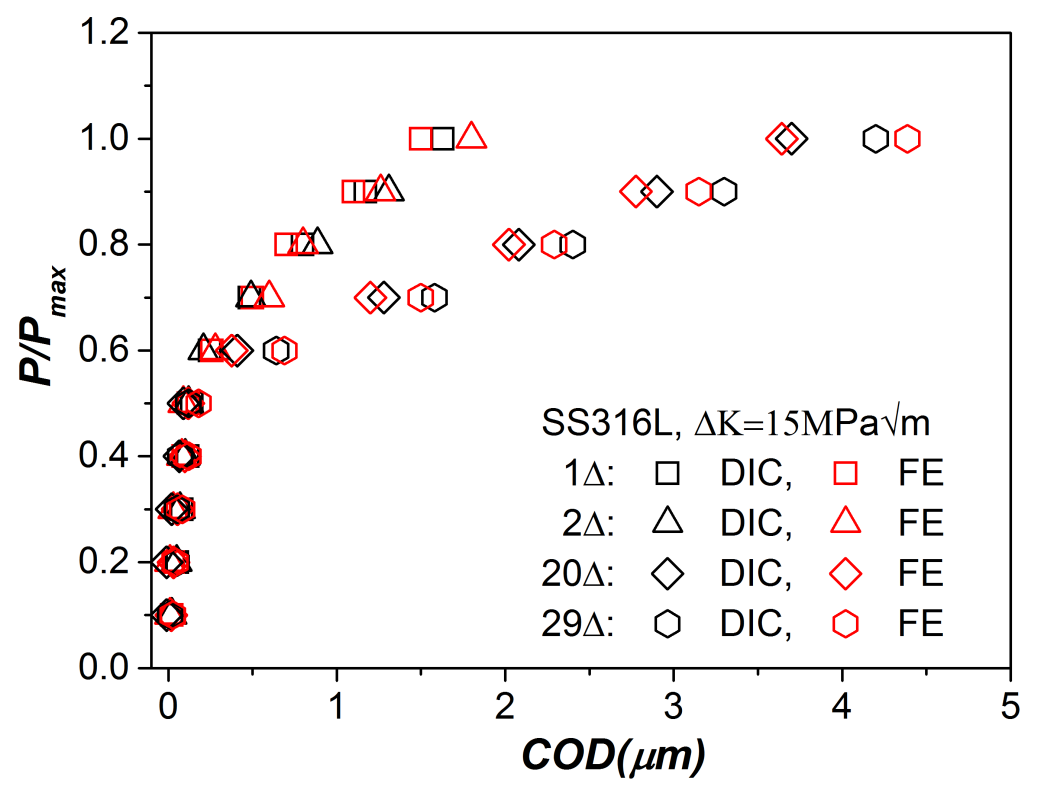

(a) 


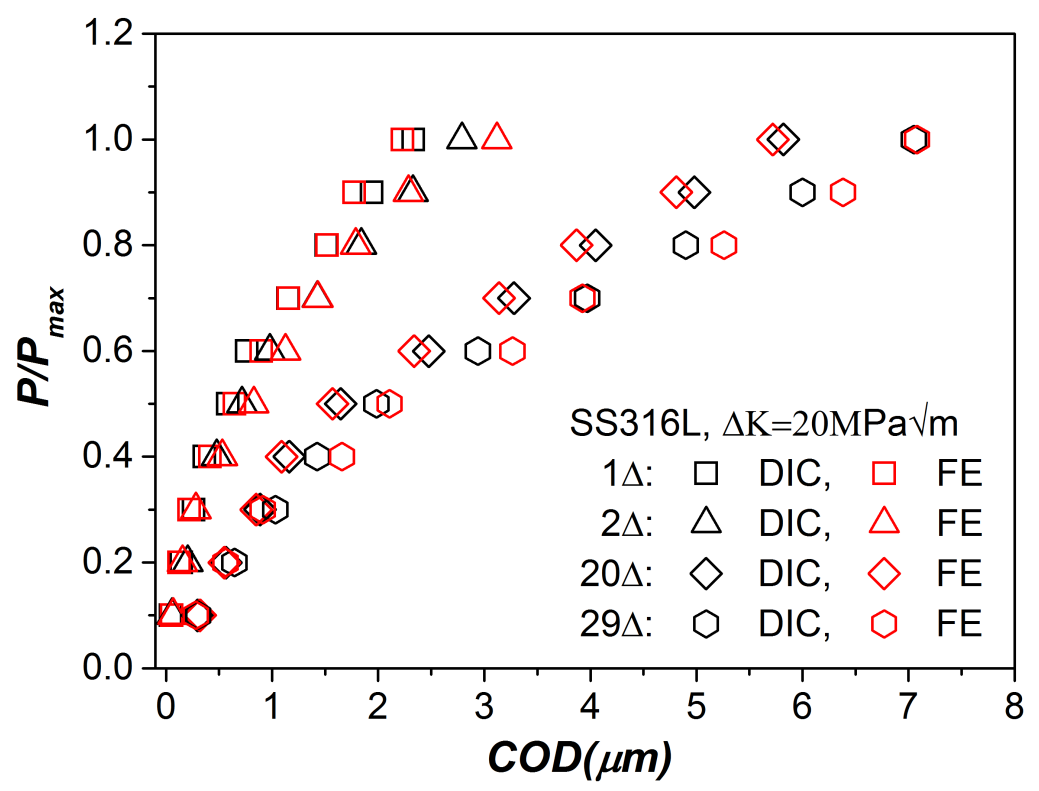

(b)

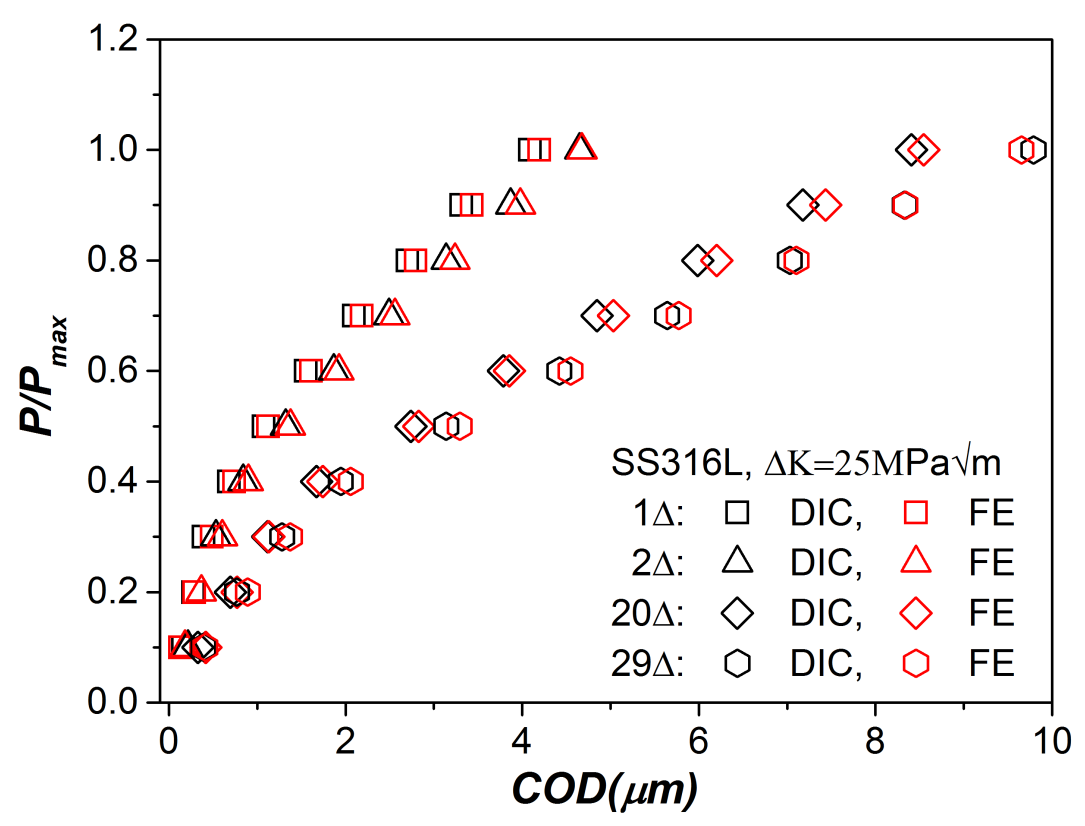

(c)

Figure 5. The crack opening displacements (CODs) obtained from the experimental measurements (DIC) and numerical simulations (FE) of SS316L specimen at the selected locations along the crack flanks (Figure 3(a)) for the three load cases: (a) $\Delta K=15 \mathrm{MPa} \sqrt{\mathrm{m}}$; (b) $\Delta K=20 \mathrm{MPa} \sqrt{\mathrm{m}}$ and (c) $\Delta K=$ $25 \mathrm{MPa} \sqrt{m}(\mathrm{R}=0.1)$. 


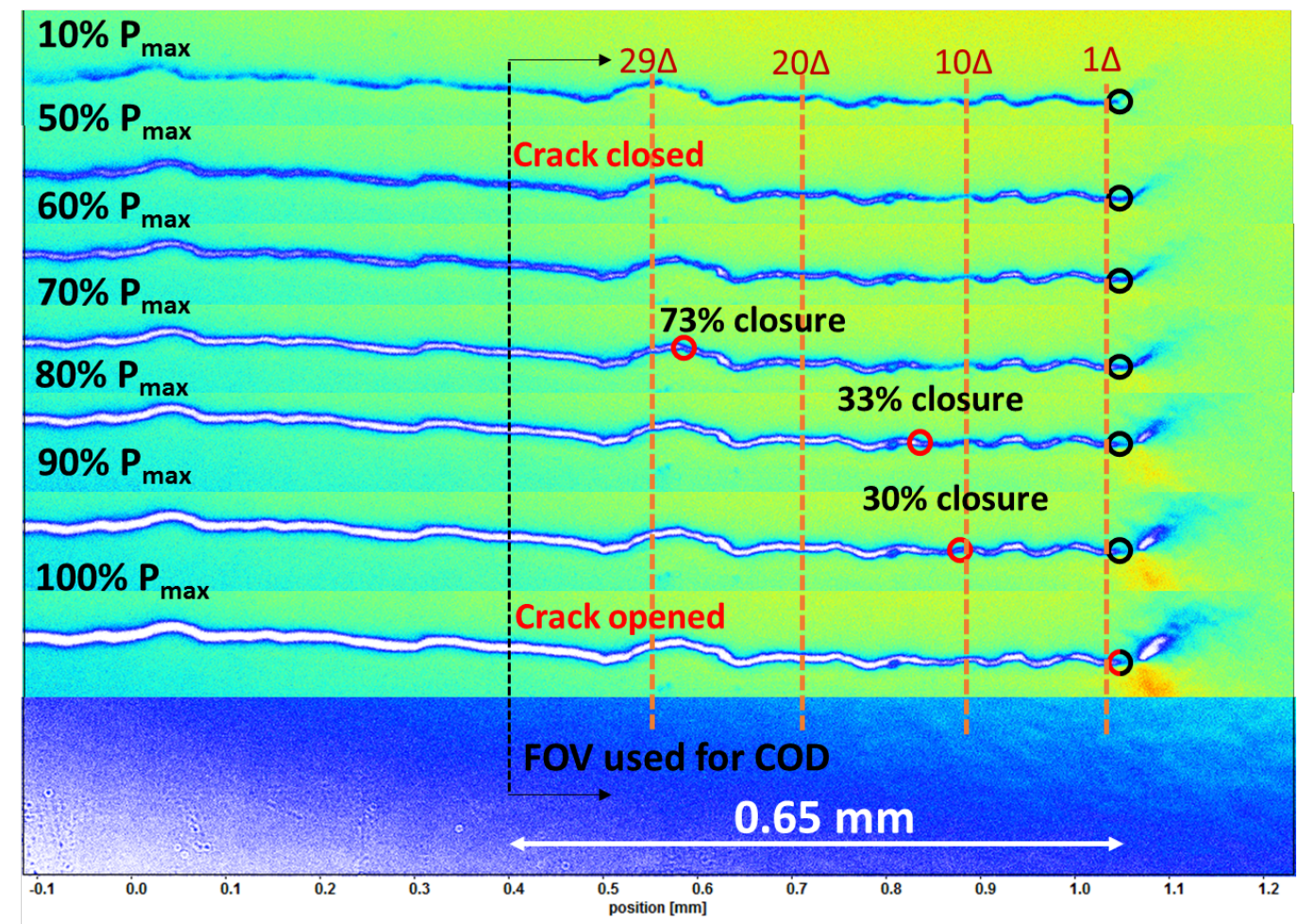

(a)

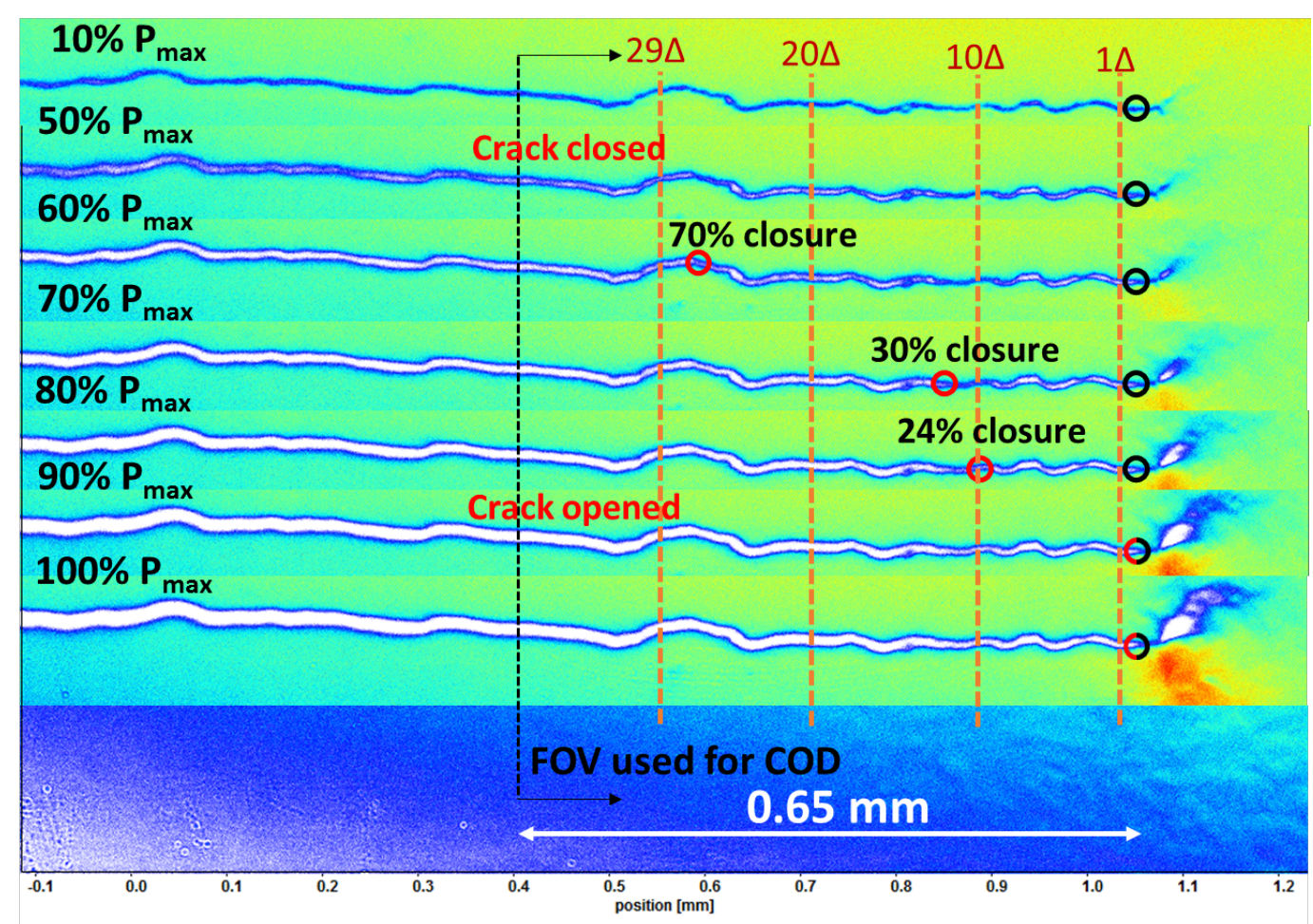

(b) 


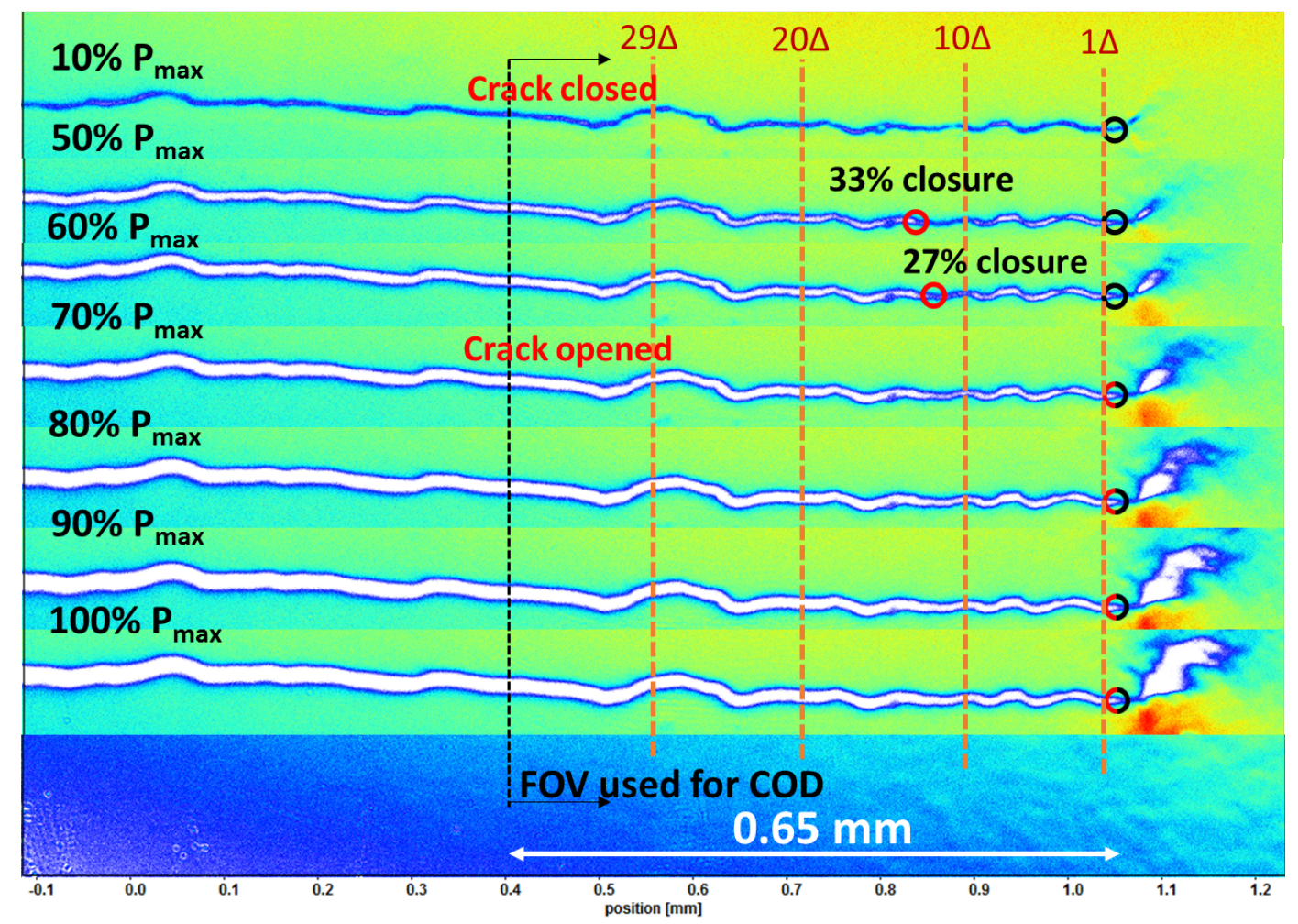

(c)

Figure 6. The visual observation of the crack profiles with the percentage of the crack flank contact during loading recorded for the three load cases: (a) $\Delta \mathrm{K}=15 \mathrm{MPa} \sqrt{\mathrm{m}}$; (b) $\Delta \mathrm{K}=20 \mathrm{MPa} \sqrt{\mathrm{m}}$ and (c) $\Delta \mathrm{K}=25 \mathrm{MPa} \sqrt{\mathrm{m}}(\mathrm{R}=0.1)$.

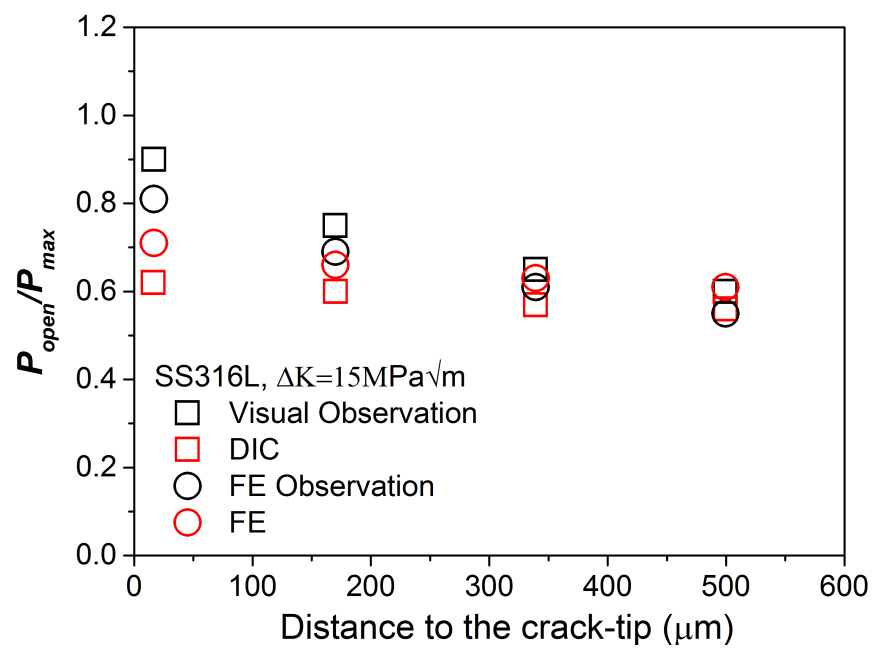

(a) 


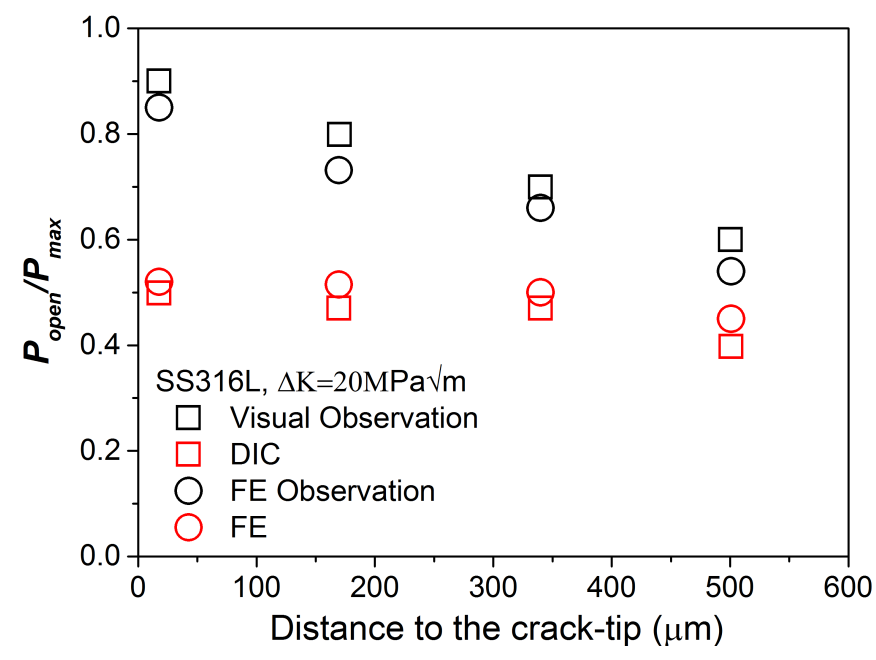

(b)

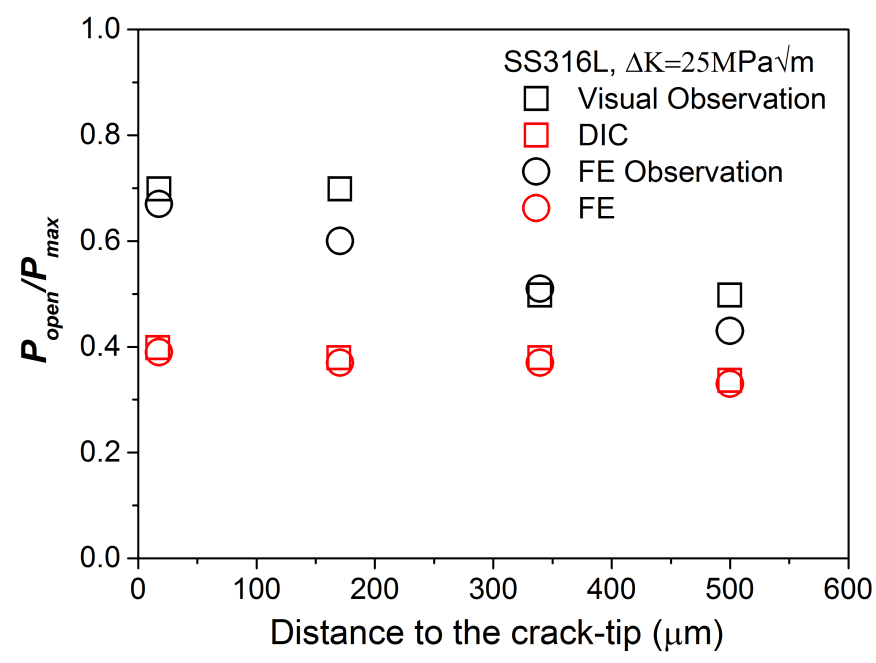

(c)

Figure 7. A summary of the "crack opening" loads as a function of distance to the crack tip using visual observation (Figure 6) and compliance curves (Figure 5) for the three load cases: (a) $\Delta \mathrm{K}=15 \mathrm{MPa} \sqrt{\mathrm{m}}$; (b) $\Delta \mathrm{K}=20 \mathrm{MPa} \sqrt{\mathrm{m}}$ and (c) $\Delta \mathrm{K}=25 \mathrm{MPa} \sqrt{\mathrm{m}}(\mathrm{R}=0.1)$. The corresponding simulated results from the $\mathrm{FE}$ analysis are also included. 


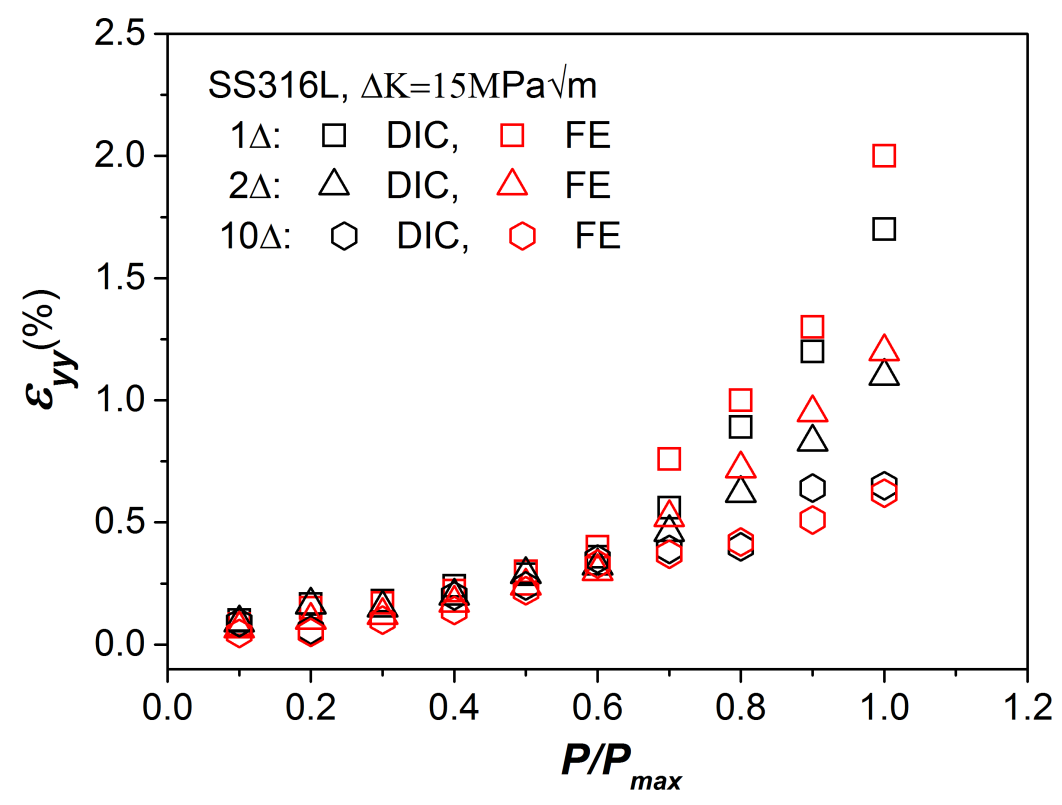

(a)

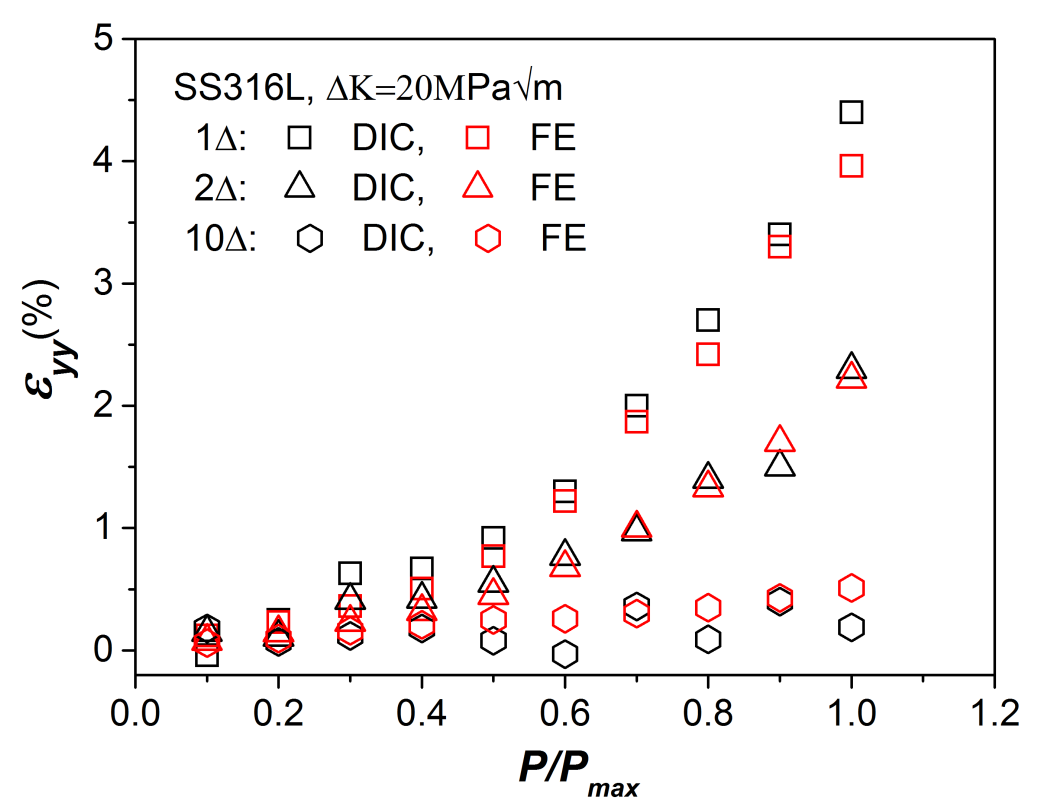

(b) 


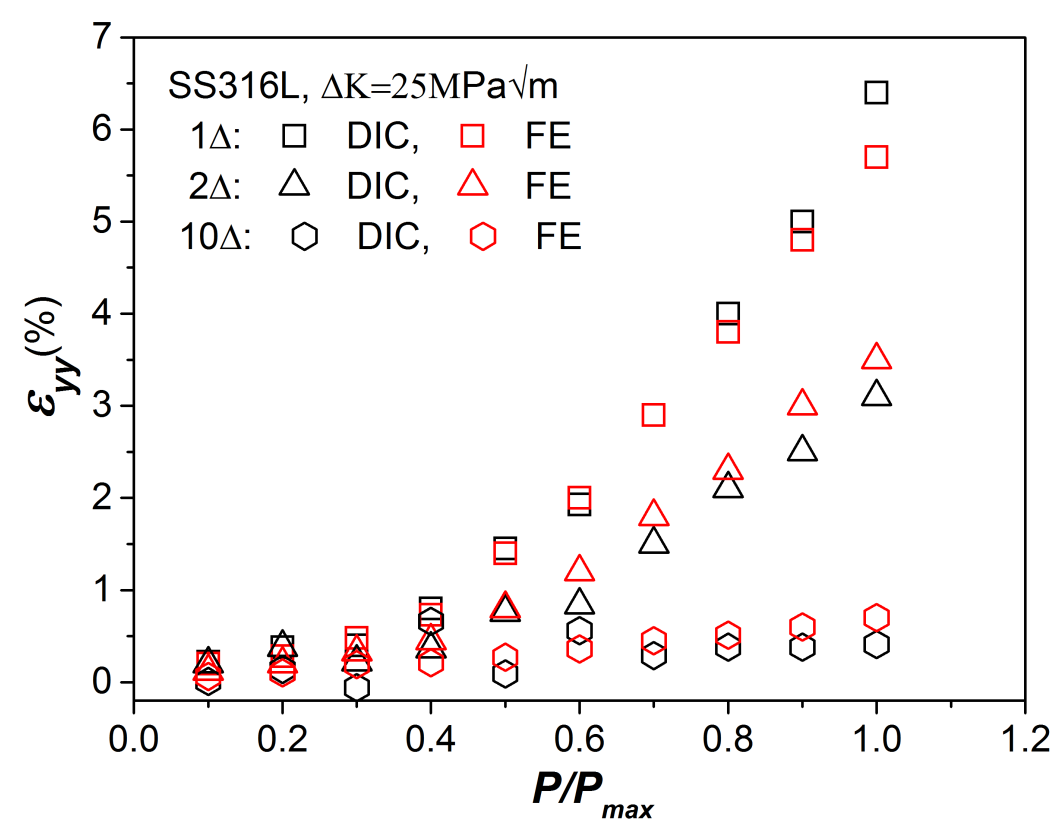

(c)

Figure 8. Comparison of the normal strains at the selected locations ahead of the crack tip (Figure 3(a)) from the experimental measurements (DIC) and the numerical simulations (FE) for the three load cases: (a) $\Delta K=15 \mathrm{MPa} \sqrt{m}$; (b) $\Delta K=20 \mathrm{MPa} \sqrt{m}$ and (c) $\Delta K=25 \mathrm{MPa} \sqrt{m}(\mathrm{R}=0.1)$.

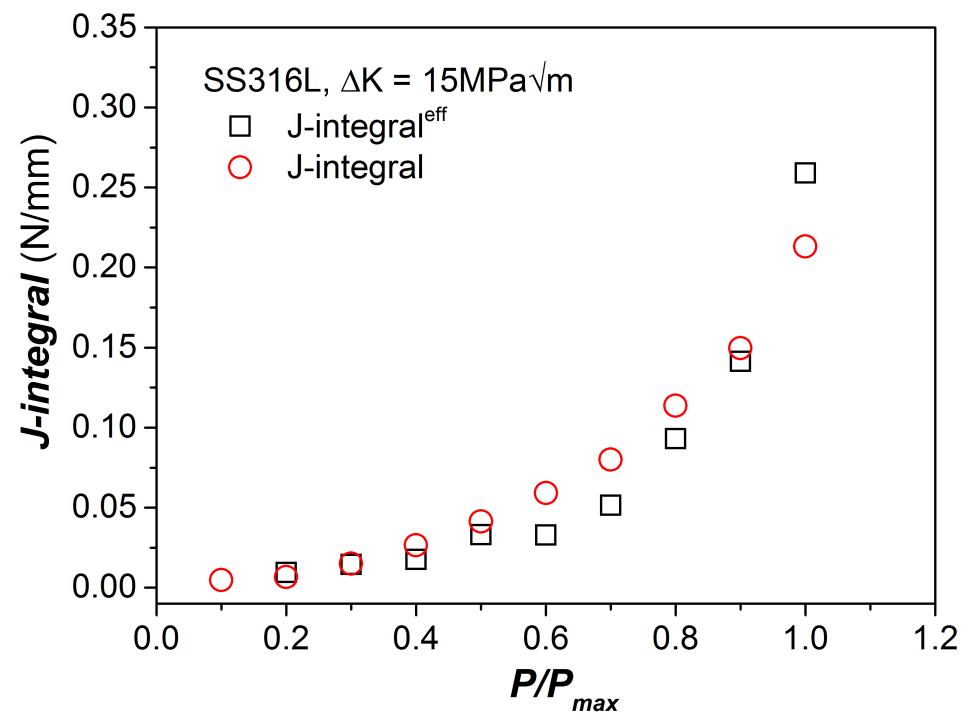

(a) 


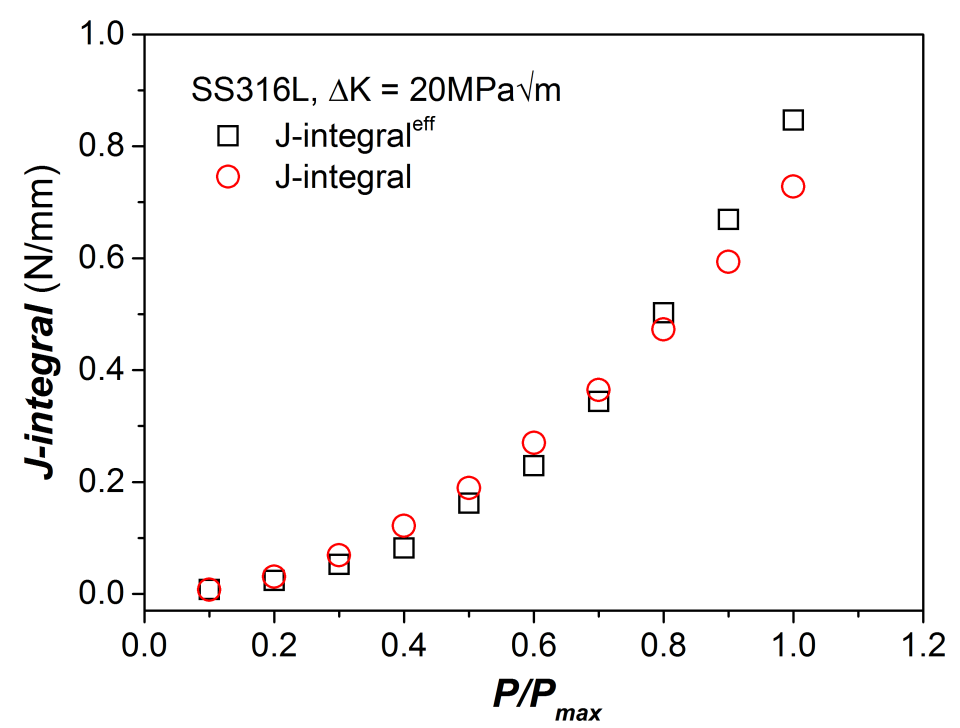

(b)

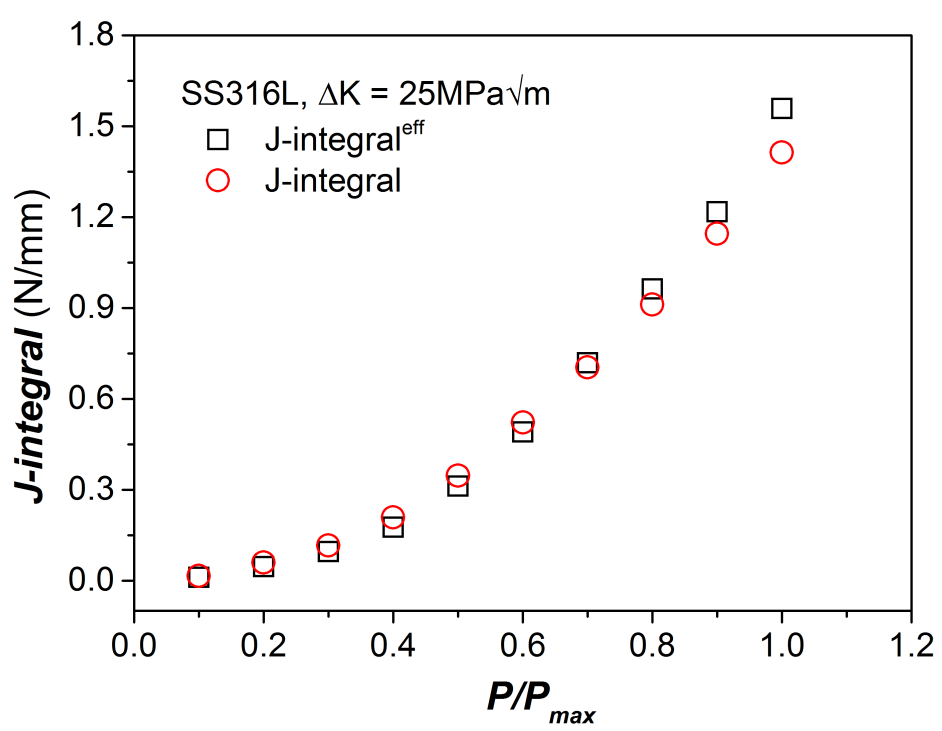

(c)

Figure 9. The J-integrals obtained from the integrated $\left(\mathrm{J}^{\mathrm{eff}}\right)$ and the standard $(\mathrm{J}) \mathrm{FE}$ analyses for the three load cases: (a) $\Delta K=15 M P a \sqrt{m}$; (b) $\Delta K=20 M P a \sqrt{m}$ and (c) $\Delta K=25 M P a \sqrt{m}$ (R=0.1). 


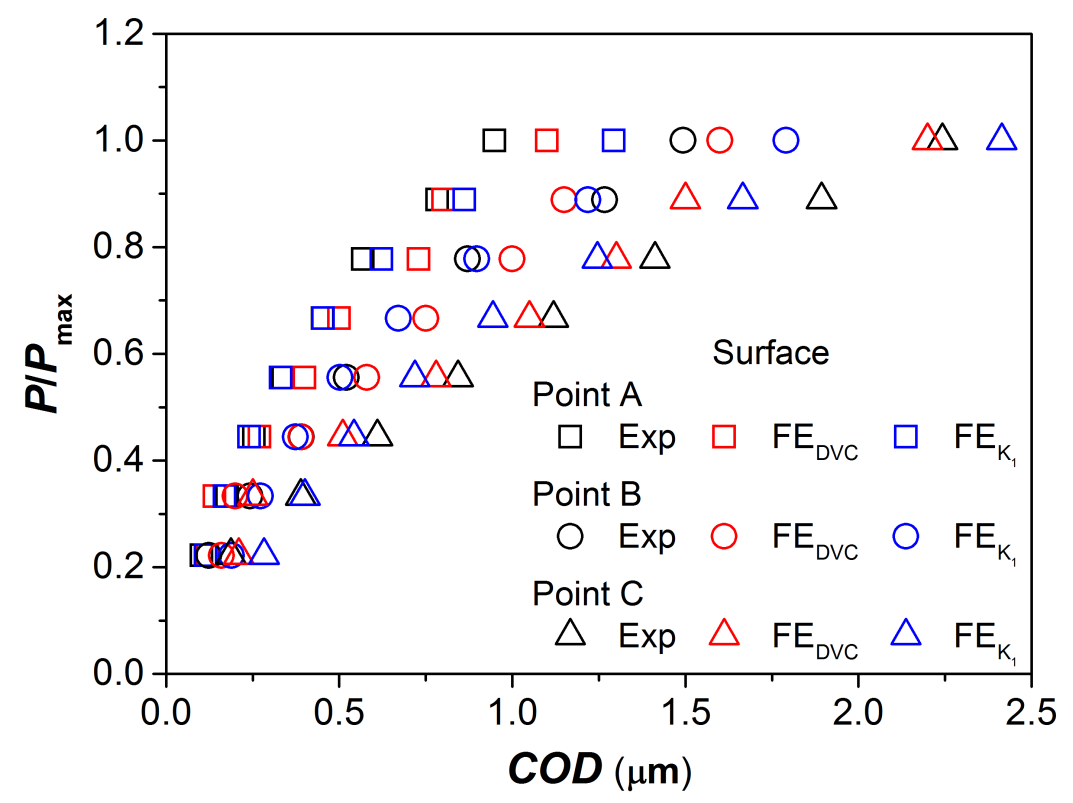

(a)

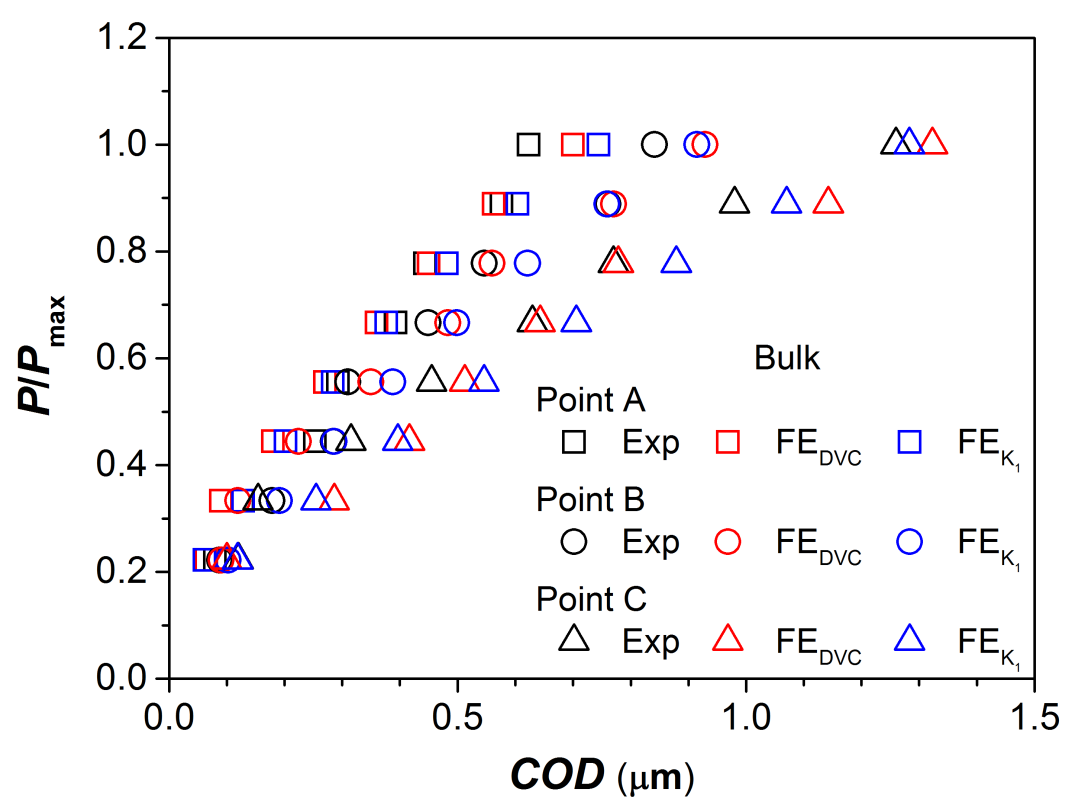

(b)

Figure 10. A summary of CODs from the DVC measurements (Exp) and numerical simulations (effective: $\mathrm{FE}_{\mathrm{DVc}}$ and nominal: $\mathrm{FE}_{\mathrm{K} 1}$ ) for the nodular cast iron specimen (Figure 2; Figure 3(b)): (a) on the surface at $\mathrm{K}_{\max } \approx 19 \mathrm{MPa} \sqrt{\mathrm{m}}$; (b) in the interior at $\mathrm{K}_{\max } \approx 16 \mathrm{MPa} \sqrt{\mathrm{m}}$. 


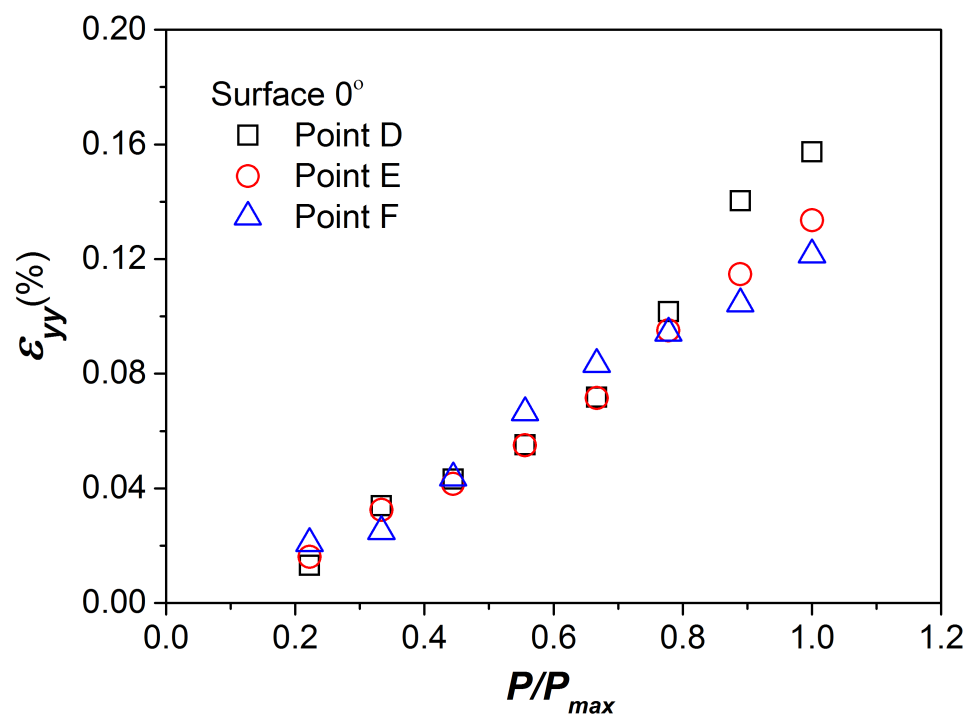

(a)

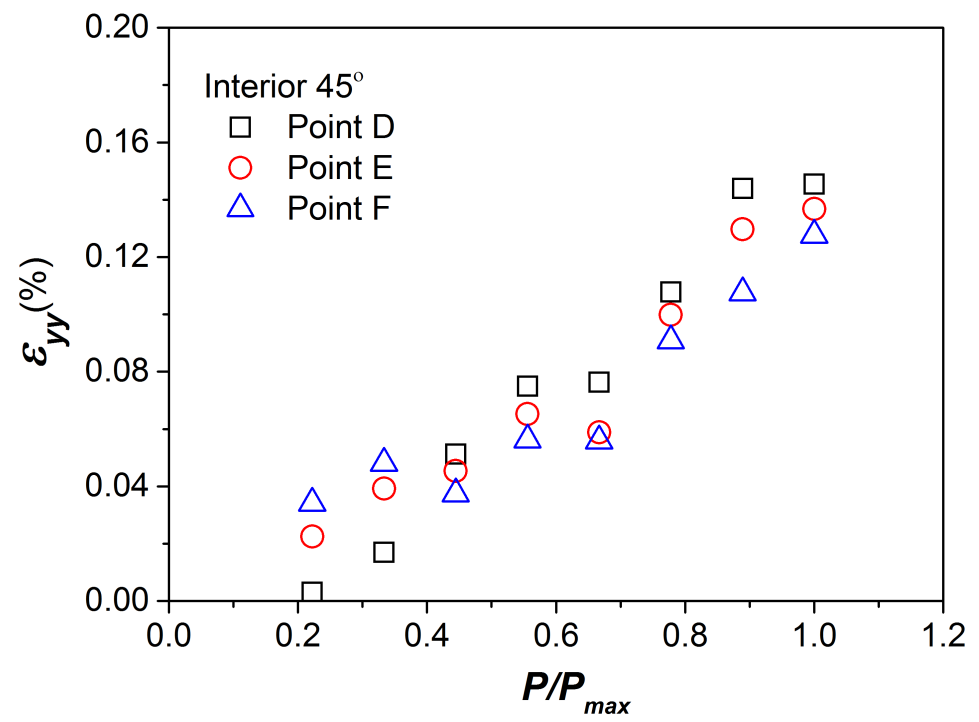

(b) 


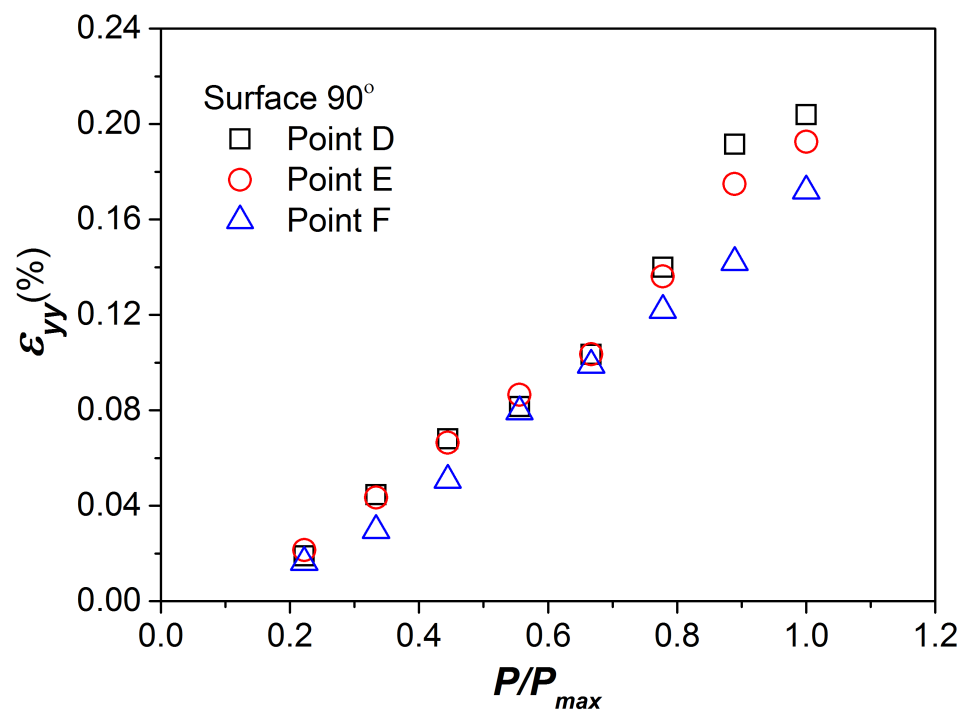

(c)

Figure 11. The normal strains as a function of applied load measured by DVC at the selected locations (Figure 3(b)) ahead of the crack tip along the direction of (a) $0^{\circ}$; (b) $45^{\circ}$ and (c) $90^{\circ}$.

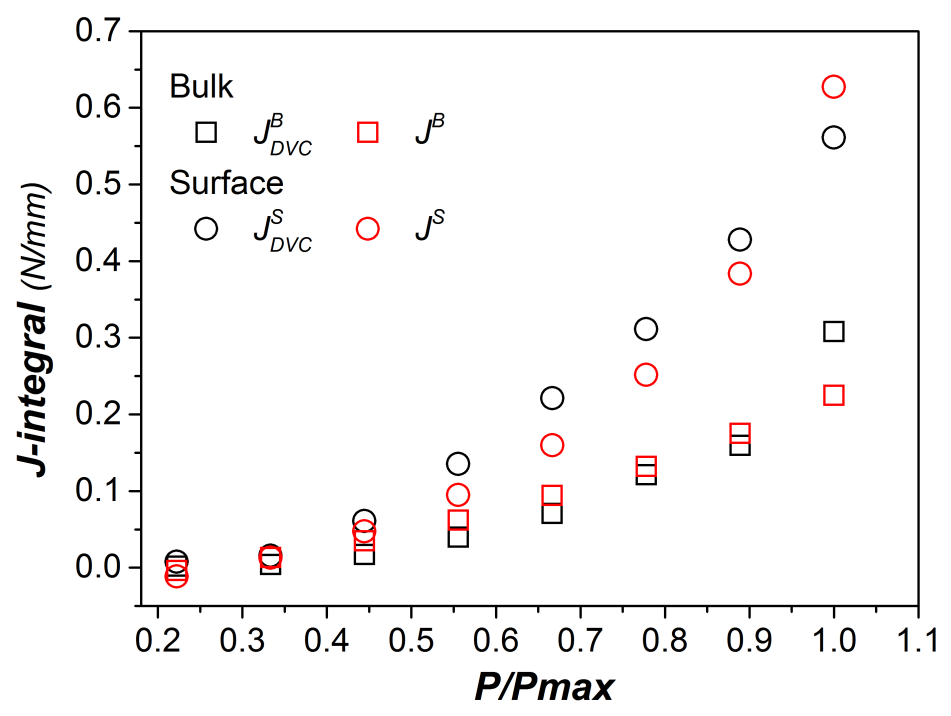

Figure 12. The J-integrals obtained from the FE analysis on the surface (S) and in the bulk (B) of the specimen, comparison of results from the effective $J_{\text {DvC }}$ (Figure $4(b)$ ) and the nominal J (Figure $4(c)$ ) calculations. 


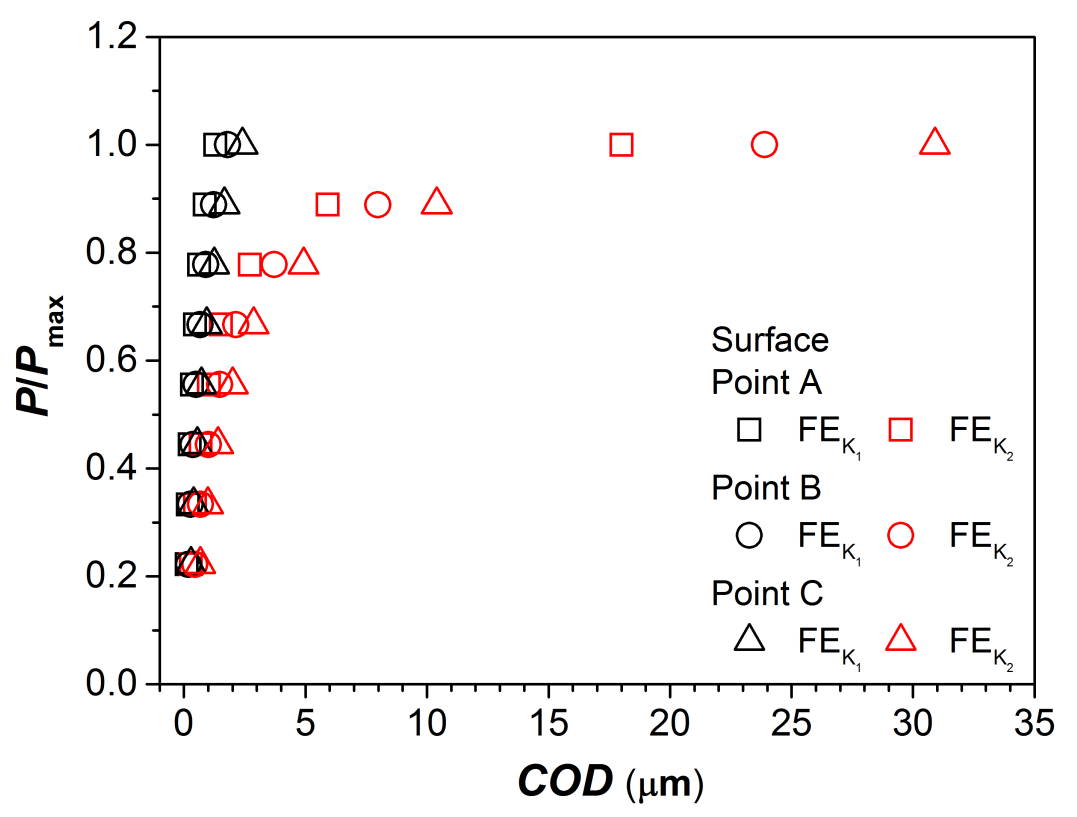

(a)

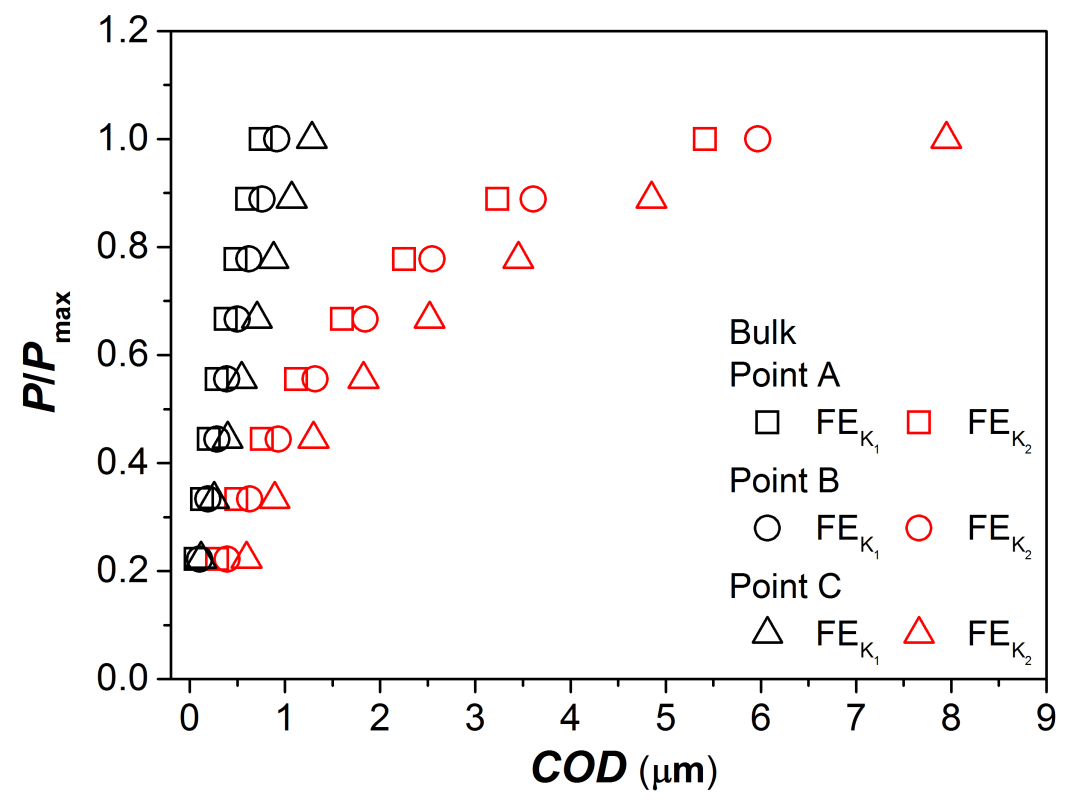

(b)

Figure 13. The FE simulated CODs for the two load cases $\left(\mathrm{K}_{1}\right.$ and $\left.\mathrm{K}_{2}\right)$ : (a) On the surface (plane stress); (b) in the interior (plane strain) of the specimen (Figure 2; Figure $4(C))$. 


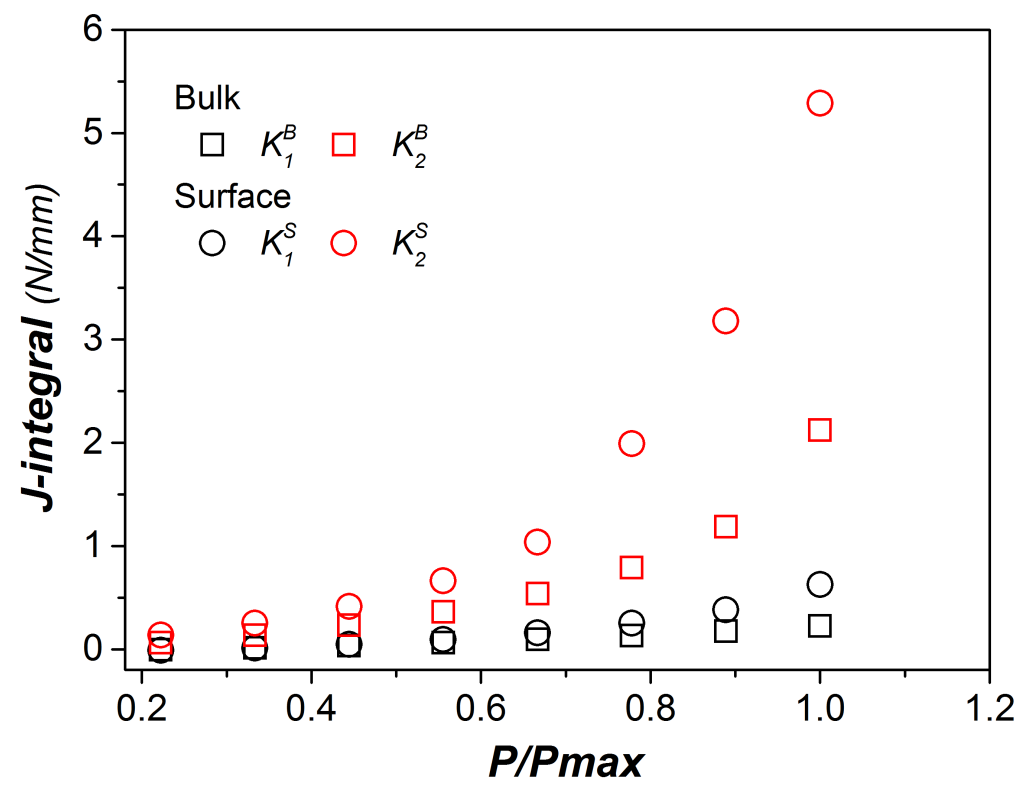

Figure 14. The J-integrals obtained for the two load cases $\left(K_{1}\right.$ and $\left.K_{2}\right)$ on the surface $(S)$ and in the interior (B) of the specimen (Figure 2; Figure 4(C)).

Table 1. The material parameters for SS316L used in the FE model

\begin{tabular}{ccccccccc}
\hline$E(G P a)$ & $v$ & $\Delta \varepsilon(\%)$ & \multirow{2}{*}{$\sigma_{0}(M P a)$} & \multicolumn{2}{c}{ Kinematic hardening } & \multicolumn{3}{c}{ Isotropic hardening } \\
\cline { 5 - 6 } & & & & $C(M P a)$ & $\gamma$ & $Q \infty(M P a)$ & $\mathrm{b}$ \\
\hline 193 & 0.3 & 4.0 & 100 & 60000 & 280 & 200 & 6 \\
\hline
\end{tabular}

